\title{
Flight Performance Feasibility Studies for the Max Launch Abort System
}

\author{
Paul V. Tartabini, ${ }^{1}$ Michael G. Gilbert, ${ }^{2}$ and James R. Beaty ${ }^{3}$ \\ NASA Langley Research Center, Hampton, VA 23681
}

\begin{abstract}
In 2007, the NASA Engineering and Safety Center (NESC) initiated the Max Launch Abort System Project to explore crew escape system concepts designed to be fully encapsulated within an aerodynamic fairing and smoothly integrated onto a launch vehicle. One objective of this design was to develop a more compact launch escape vehicle that eliminated the need for an escape tower, as was used in the Mercury and Apollo escape systems and what is planned for the Orion Multi-Purpose Crew Vehicle (MPCV). The benefits for the launch vehicle of eliminating a tower from the escape vehicle design include lower structural weights, reduced bending moments during atmospheric flight, and a decrease in induced aero-acoustic loads. This paper discusses the development of encapsulated, towerless launch escape vehicle concepts, especially as it pertains to the flight performance and systems analysis trade studies conducted to establish mission feasibility and assess system-level performance. Two different towerless escape vehicle designs are discussed in depth: one with allpropulsive control using liquid attitude control thrusters, and a second employing deployable aft swept grid fins to provide passive stability during coast. Simulation results are presented for a range of nominal and off-nominal escape conditions.
\end{abstract}

\section{Nomenclature}

$\begin{array}{ll}\text { ACS } & =\text { Attitude Control System } \\ \text { ConOps } & =\text { Concept of Operations } \\ \text { c.g. } & =\text { center of gravity } \\ \text { c.p. } & =\text { center of pressure } \\ C M & =\text { Crew Module } \\ \text { L/D } & =\text { Lift to drag ratio } \\ \text { MLAS } & =\text { Max Launch Abort System } \\ \text { OS-1 } & =\text { Objective System } 1 \text { Concept } \\ \text { OS-2 } & =\text { Objective System } 2 \text { Concept } \\ \text { Q-Alpha-Total } & =\text { Product of dynamic pressure and total angle of attack } \\ \text { RCS } & =\text { Reaction Control System } \\ \text { TVC } & =\text { Thrust Vector Control }\end{array}$

\section{Introduction}

$\mathrm{T}$ he safety of the flight crew during launch is a prime consideration in the design of systems to provide human access to space. For the NASA-developed Mercury and Apollo and Russian Soyuz systems, a single towerbased solid auxiliary rocket motor attached to the front of the crew module provided the means for separating the crew from a failing launch vehicle. ${ }^{1-2}$ Recently, NASA has begun development of a similar tower-based configuration for the Orion Multi-Purpose Crew Vehicle spacecraft. ${ }^{3}$ However, because of increases in the crew complement and the desire for more robust abort performance, the subsequent tower-based escape system designs have increased in complexity and have had a significant effect on the design and flight characteristics of the integrated launch vehicle. Specifically, escape tower configurations adversely affect the drag and bending moments of the launch vehicle during atmospheric flight, as well as its overall structural weight and increased induced aero-acoustic

\footnotetext{
${ }^{1}$ Aerospace Engineer, Vehicle Analysis Branch, 1 North Dryden Street, Mail Stop 451, Member

${ }^{2}$ Principal Engineer, NASA Engineering and Safety Center, 11 Langley Blvd, Mail Stop 116, Associate Fellow

${ }^{3}$ Aerospace Engineer, Vehicle Analysis Branch, 1 North Dryden Street, Mail Stop 451, Member
}

1

American Institute of Aeronautics and Astronautics 
loads. In addition, for the tower configurations with a single abort rocket motor, the required thrust level is set by the worst case abort condition (typically maximum drag or maximum dynamic pressure) and can result in excess gloading to the crew and crew module structure when abort conditions are more benign, such as from the launch pad. Finally, tower-based configurations have large pitch and yaw moments of inertia that require a significant control moment capability and forward-positioned escape motors that expose the crew module to significant levels of plume impingement.

In 2007, the NASA Engineering and Safety Center (NESC) initiated the Max Launch Abort System (MLAS) Project, which was named for Maxime (Max) Faget, designer of the Mercury Capsule. The objective of the MLAS project was to explore crew escape system concepts that did not make use of the conventional tower-configuration approach employed in the Mercury and Apollo spacecraft. Instead, the MLAS crew escape system is designed to be fully encapsulated within an aerodynamic fairing that smoothly integrates into the launch vehicle (Fig. 1). In addition to improved integration, eliminating the escape tower provides a more compact escape system that improves both launch vehicle aerodynamics and maneuverability during an escape. Moreover, the MLAS system concepts make use of multiple, aft-mounted escape motors that greatly reduce plume impingent issues and can be easily scaled to accommodate larger, heavier crew capsules.

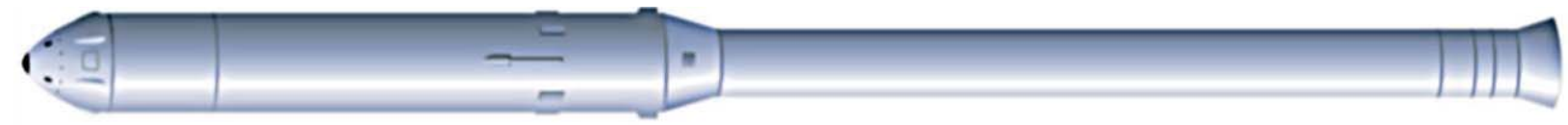

Figure 1. Launch vehicle.

In 2009 a successful pad abort flight test of a passively stable MLAS escape vehicle concept was completed at the NASA Wallops Flight Facility. The test demonstrated a number of key abort functions critical to the MLAS design such as stable coast flight following abort motor burnout, jettison of the coast phase stabilizing aerodynamic surfaces prior to vehicle reorientation, and deployment of the reorientation and recovery parachute systems. ${ }^{4}$

The 2009 flight test was part of a broader objective system design study that examined several towerless escape vehicle concepts capable of meeting all human spaceflight launch vehicle abort requirements over a range of different flight regimes. The purpose of this paper is to discuss the vehicle concept development, especially as it pertains to the flight performance and systems analysis trade studies that were conducted to establish mission feasibility and assess system-level performance. Two different towerless escape system designs are discussed: one with an allpropulsive attitude control system that utilizes liquid propellant thrusters, designated as Objective System 1 (OS-1); and a second employing deployable aft swept grid fins to provide passive stability during coast, designated as Objective System 2 (OS-2). Figure 2 shows drawings of these two concepts. In addition, the development of a detailed six degree of freedom (6DOF) simulation of both concepts is described and simulation study results are detailed with regard to motor sizing, stability and control requirement definition, concept of operations design, and the establishment of overall concept feasibility.

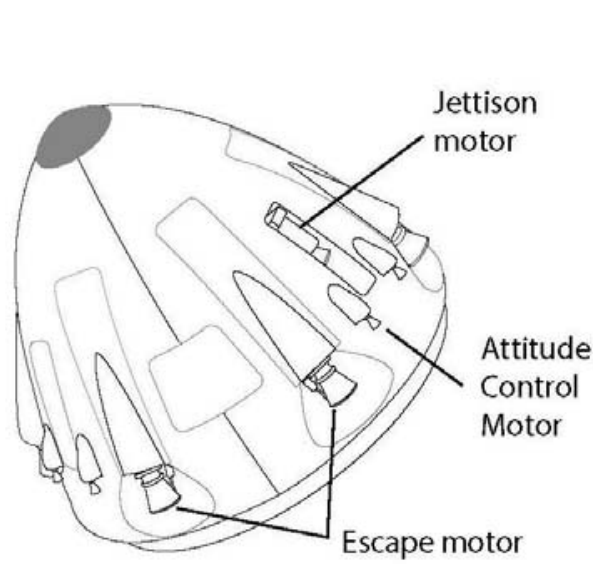

OS 1

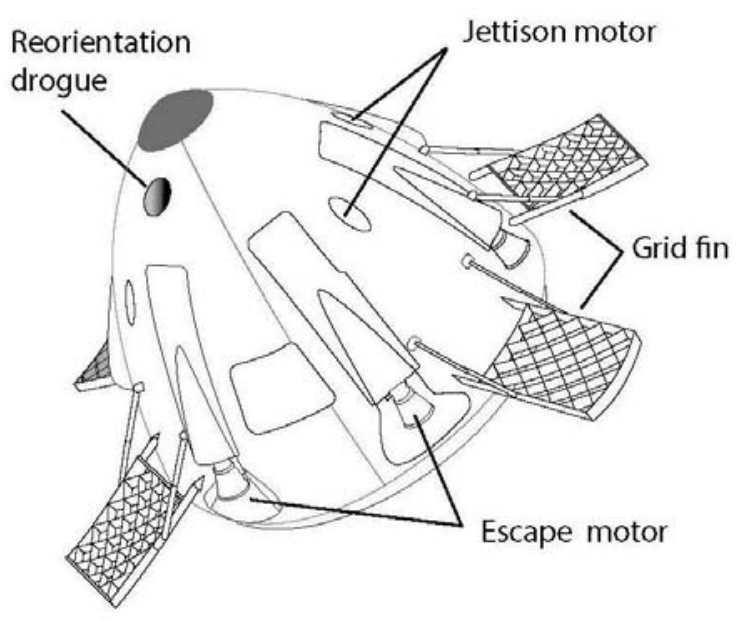

OS 2

Figure 2. Two different towerless escape vehicle designs. 


\section{Concept Definition}

\section{A. Study Approach}

By its nature crew escape requires highly dynamic flight trajectories. Consequently, a high-fidelity six-degreeof-freedom trajectory simulation was required to accurately assess the feasibility and controllability of the different escape system concepts that were investigated.

Throughout the course of the study, system performance was simulated and evaluated at four critical points along a representative launch vehicle trajectory, assuming both nominal and off-nominal conditions. These test points included 1) an off-the-pad escape trajectory (pad abort) that required large maneuvers to meet stringent altitude and downrange requirements; 2) escape at transonic conditions where suction drag effects inhibiting separation from the launch vehicle were highest; 3 ) escape at maximum dynamic pressure, when the highest vehicle loads occurred; and 4) a high attitude escape at exo-atmospheric conditions. The launch vehicle trajectory assumed was similar to an Ares I ascent trajectory, but the escape conditions at the test points are sufficiently rigorous so that results are applicable to other launch vehicles. Table 1 lists the altitude, Mach number, and dynamic pressure of these test cases.

Table 1. Escape Trajectory Test Case Conditions

\begin{tabular}{|l|l|l|l|}
\hline Escape Vehicle Simulation Test Cases & Altitude (ft) & Mach & $\begin{array}{l}\text { Dynamic Pressure } \\
\text { (psf) }\end{array}$ \\
\hline \hline Pad Escape & 0 & 0.0 & 0 \\
Transonic Escape & 19,200 & 1.0 & 740 \\
Maximum Dynamic Pressure Escape & 43,700 & 1.9 & 910 \\
High Altitude Escape & 185,000 & 6.2 & 20 \\
\hline
\end{tabular}

Simulation analyses were conducted at these test points to de-

termine the flight dynamic feasibility of various towerless escape system concepts. Concept viability and crew escape performance were evaluated by assessing controllability at the four test cases and verifying that a set of typical abort performance requirements (see Table 2) could be satisfied. The two concepts described in this paper were the result of multiple design iterations that were performed to adjust the configuration layout, motor sizes, and concept of operations until all performance requirements could be met.

Table 2. Representative Escape System Performance Requirements

\begin{tabular}{|l|l|}
\hline Abort Type & Requirement \\
\hline \hline Pad Abort & $\begin{array}{l}\text { Mean Sea Level Altitude }>3,500 \mathrm{ft} \text { at fairing jettison } \\
\text { Downrange distance }>3,500 \mathrm{ft} \text { at fairing jettison }\end{array}$ \\
\hline Ascent Abort & $\begin{array}{l}\text { Separation distance between abort vehicle and launch vehicle }>175 \mathrm{ft} \\
\text { within three seconds of abort initiation }\end{array}$ \\
\hline All Aborts & $\begin{array}{l}\text { Maintain stability throughout abort trajectory without excessive alpha, } \\
\text { beta or body rate excursions } \\
\text { Max. Q-Alpha-Total }<10,000 \text { psf-deg } \\
\text { Thrust vector control deflections }<15 \text { deg and slew rates }<200 \mathrm{deg} / \mathrm{s} \\
\text { Attitude control system propellant usage }<95 \% \text { of available }\end{array}$ \\
\hline
\end{tabular}

\section{B. Abort Mission Profile}

The two MLAS escape system concepts investigated in this paper are designed to provide an escape/rescue capability for a capsule Crew Module (CM) similar to the Orion Multi-purpose Crew Vehicle. Both MLAS concepts contain a fairing that covers or encapsulates the CM capsule, as well as multiple solid rocket escape motors that are attached to the fairing and which provide the impulse necessary to separate the CM from a failing launch vehicle and maneuver it to safety. The escape system concepts are designed to provide an escape capability at all speeds and altitudes during ascent, but are especially suited to provide escape from off-the-pad prelaunch failures as well as failures occurring during high acceleration segments of ascent at altitudes where atmospheric forces are significant. 
The only purpose of the crew escape system is to remove the $\mathrm{CM}$ from a failing launch vehicle. Thus, it is assumed that once the escape system has successfully maneuvered the CM to a safe state at a sufficient distance away from the failure, the escape system fairing is jettisoned, and the CM descent and landing systems perform their required functions. During nominal operation, the CM enters the atmosphere and descends with the heat-shield-forward using its reaction control system (RCS) jets for stabilization and control, eventually deploying parachutes that are mounted near the capsule apex for final descent and landing. In the event of an ascent abort at low and mid altitudes, the escape system is designed to reorient the CM to its heat-shield-forward entry attitude after it has maneuvered the CM away from the launch vehicle. For failures at higher altitudes when atmospheric forces are sufficiently small, it is assumed that the CM's RCS will be used to reorient the CM to its descent attitude prior to atmospheric interface. Specific details on the concept of operations for each of the two escape system concepts are provided in the next sections.

\section{OS-1: All Propulsive Escape System Concept}

The OS-1 escape system shown in Fig. 1 is an all-propulsive, actively controlled crew escape system concept that integrates six solid rocket motors with thrust vector control mechanisms into an aerodynamically shaped fairing that encapsulates the CM. The escape system's integrated aerodynamic/structural fairing acts as an aerodynamically clean, low-drag forward-end shape to the launch vehicle while providing structural support for the abort motor thrust, thrust-vector control, and attitude control forces during an abort. The fairing uses a modified Sears-Haack shape, which yields low aerodynamic drag for a given enclosed volume and provides sufficient capacity to house eight liquid-propellant attitude control system (ACS) pulse-jet thrusters and associated tanks, pipes, and valves. The fairing also houses and provides structural support for three small solid-rocket jettison motors that remove the escape system from the launch vehicle when it is no longer needed for a nominal launch, and, during an abort, separate the fairing from the CM to allow for its controlled descent. Figure 3 shows the overall dimensions of the OS-1 concept that was studied in this paper.

\section{Concept of Operations}

The concept of operations developed for the OS-1 crew escape system includes provisions for crew escape from: 1) pad or low-altitude launch vehicle failures, 2) mid-altitude failures during ascent including transonic or maximum dynamic pressure failures, 3) failures during ascent at high altitudes, and 4) jettison of the escape system during nominal (no failure) launches. The analysis in this paper assumed an Ares I launch vehicle with an Orion Crew Module launched from Kennedy Space Center's Launch Complex 39 pad B.

During a nominal launch, the solid rocket escape motor nozzles, ACS thruster nozzles, and solid rocket jettison motor nozzles are covered by panels that maintain the clean aerodynamic shape of the fairing. In the event of a launch vehicle failure, these panels are immediately ejected (prior to escape motor startup) using explosive bolts or springs. After panel removal but before escape motor ignition, the escape motor Thrust Vector Control (TVC) system activates and deflects the nozzles outward from their stowed position (their position during a nominal launch, when they are defected inward to reduce their profile and permit a smooth outer mold line) to their initial thrusting orientation. The initial thrusting orientation is different for each nozzle to minimize thrust torques during escape motor startup. The initial orientations are predetermined based on the combined mass properties of the CM and escape system. Once the panels are removed and the nozzles are aligned, the escape motors are ignited and the escape trajectory is initiated. The same pre-ignition sequence is followed for each type of escape (pad/low-altitude, midaltitude and high-altitude); however, the events after escape motor ignition differ, depending on the type of escape, and are described next. 


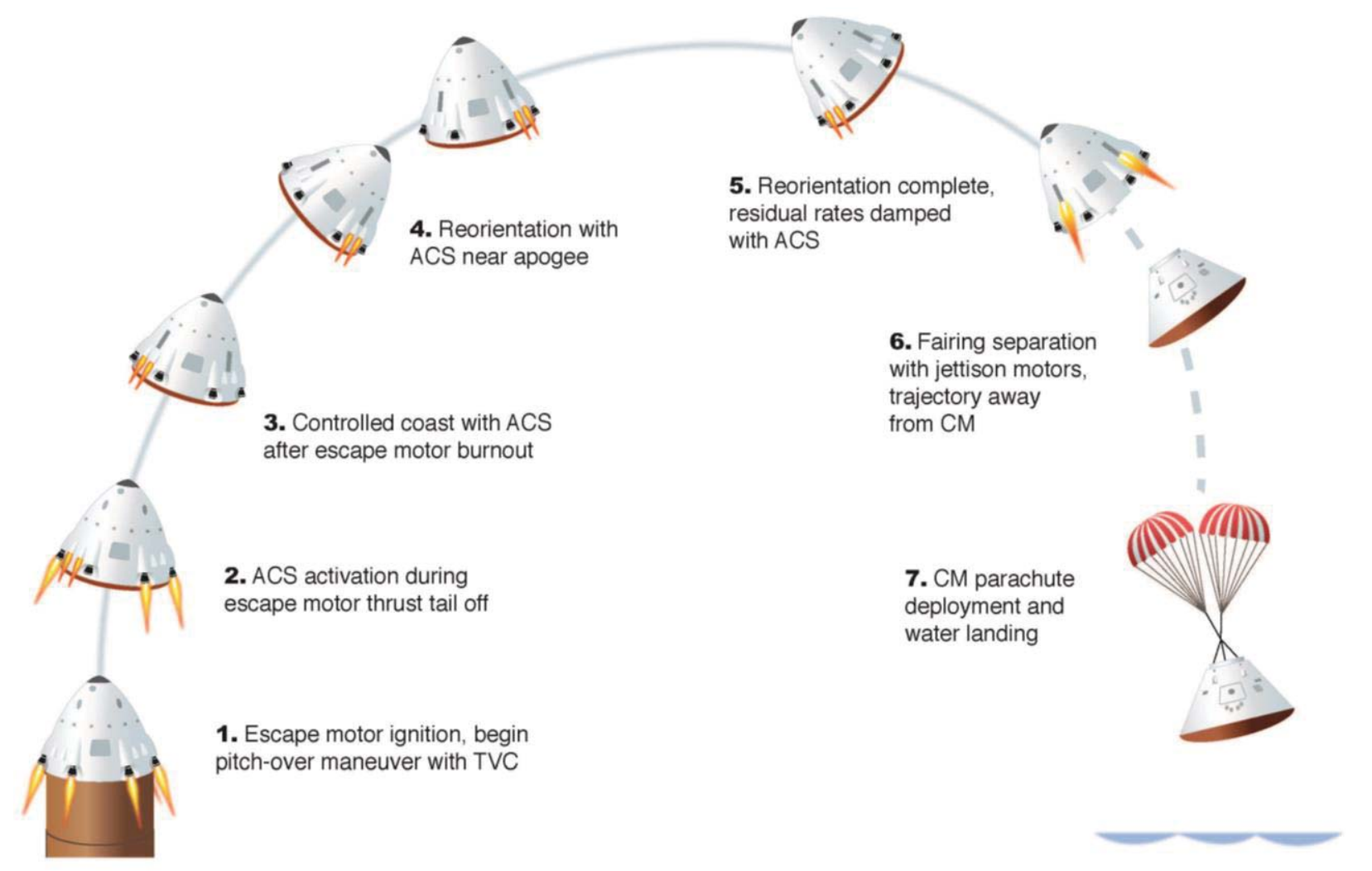

Figure 4. OS-1 concept of operations for pad and low altitude escape.

Figure 4 shows the OS-1 Concept of Operations (ConOps) for escape due to a prelaunch emergency on the pad or a low-altitude launch vehicle failure, beginning at escape motor ignition. First, the six escape motors ignite, and a controlled pitch-over maneuver is performed with TVC. The maneuver places the escape vehicle on a trajectory perpendicular to the shoreline and is designed to provide sufficient altitude and down range from the coastline to allow a parachute landing of the capsule into the ocean at a safe water depth. As the thrust of the solid rocket escape motors begin to tail off prior to burnout, the ACS thrusters become operational and act in concert with the escape motor TVC to stabilize the vehicle and counteract thrust dispersions. After the escape motors fully burnout, the control thrusters continue to maintain a stable coast until the vehicle is close to apogee, when a reorientation maneuver is performed to properly position the parachutes for deployment. After reorientation, the ACS thrusters damp out residual body rates until a stable heat shield forward attitude is attained. At this point the ACS thrusters are shut off and the jettison motors ignite to separate the escape fairing from the CM, placing it on a trajectory that avoids interference with crew module recovery system operations. After fairing jettison the crew module parachutes are immediately deployed, resulting in a water landing in the ocean.

The ConOps for escape due to mid-altitude launch vehicle failures occurring during ascent, including launch vehicle failures at transonic or maximum dynamic pressure conditions, includes the same events shown in Fig. 4 for pad or low-altitude escapes. There are three notable differences in the details and timing of these events. First, a smaller initial pitch-over maneuver is performed during the escape motor boost portion of the crew escape vehicle trajectory to induce some lateral separation from the launch vehicle flight path. Instead of flying perpendicular to the coastline, the escape vehicle flies a trajectory to maximize the separation distance from the launch vehicle (assuming that the launch vehicle drag and flight path did not change after the abort). Second, the reorientation of the crew escape vehicle occurs later in the timeline to allow the dynamic pressure to decay naturally to levels that are within ACS control motor torque capability. Finally, after fairing jettison the crew module coasts under its own RCS control until it reaches the design altitude for parachute deployment. 


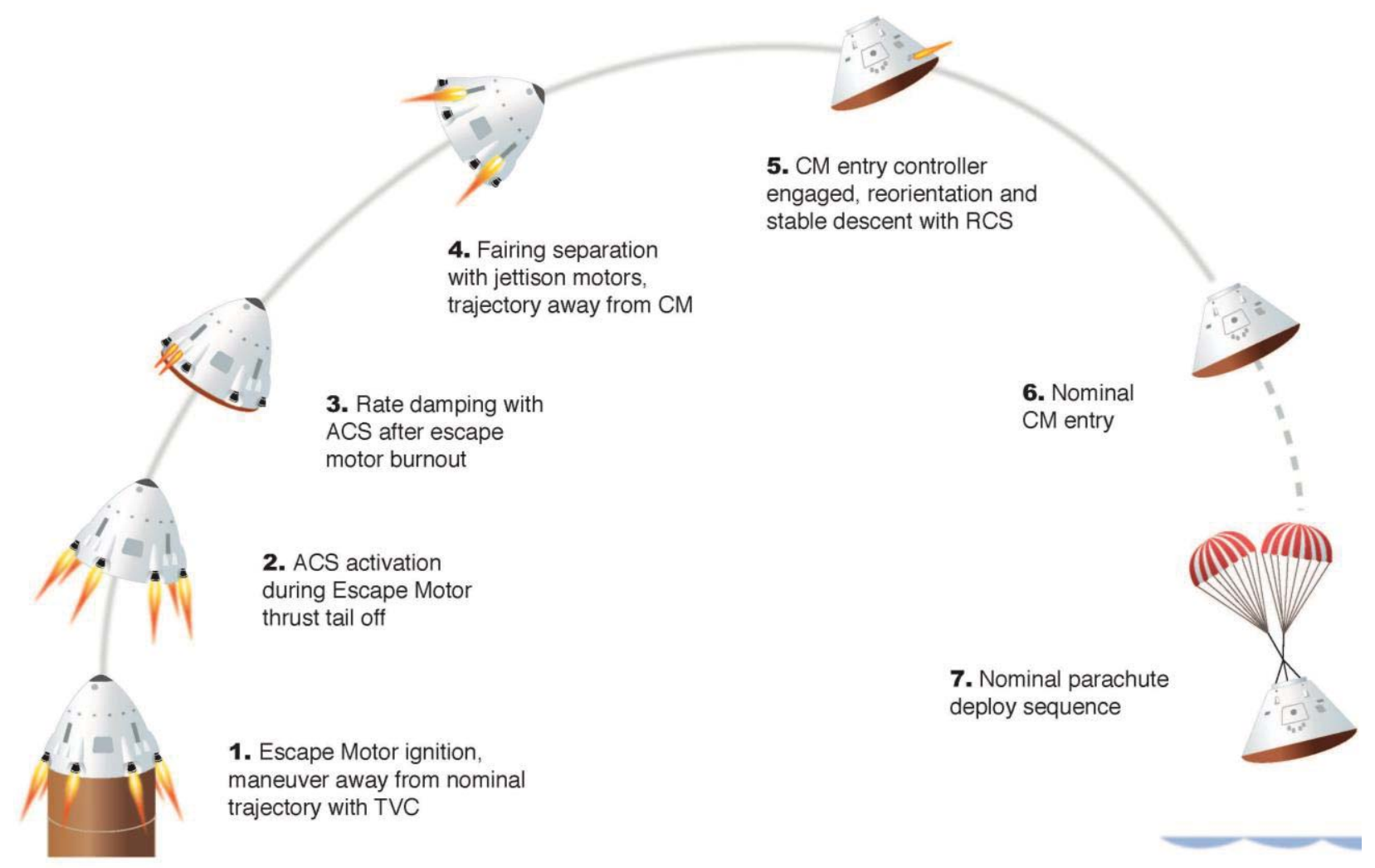

Figure 5. OS-1 concept of operations for high altitude escape.

High-altitude escapes are performed at or near exo-atmospheric conditions, when aerodynamic forces are negligible. The ConOps for high-altitude escapes differs from the previous escape types in that there is less coast time, the escape system fairing is jettisoned prior to CM reorientation, and the CM's RCS performs the reorientation maneuver. The OS-1 high-altitude escape sequence (Fig. 5) begins as the six escape motors ignite, and TVC is used to perform a small maneuver to induce lateral separation from the launch vehicle flight path. The ACS thrusters activate prior to escape motor burnout when the thrust is tailing off to damp out any oscillations due to thrust dispersions. As soon as rates are damped, the ACS is turned off, and the jettison motors ignite to remove the fairing while the $\mathrm{CM}$ is still in a nose-forward orientation. At this point the CM entry controller is engaged, and reorientation to a heat-shield forward attitude is performed using its RCS once the CM is clear of the jettisoned fairing. At this point the CM follows its nominal entry procedures using RCS to provide a stable descent to the nominal parachute deployment altitude, at which point normal landing and recovery procedures are followed.

During a nominal launch when there is no failure, the crew escape system is jettisoned to increase payload capability when critical events like maximum dynamic pressure and staging have passed and it is no longer needed to ensure a safe escape. The precise time of escape system jettison depends on the specific launch vehicle and crew vehicle designs, but will likely occur when ascent trajectory conditions are benign enough to allow the crew vehicle to perform an escape using its own propulsion systems. For this study in which the Orion CM and Ares I trajectory were assumed, nominal jettison for the OS-1 was designed to occur 30 seconds after stage separation at near exoatmospheric altitudes exceeding 250,000 ft. The concept of operations for a nominal jettison of the OS-1 escape vehicle is shown in Fig. 6. Separation is initiated when the three jettison motors are ignited to separate the fairing from the CM. In addition to providing separation distance from the ascending $\mathrm{CM}$, the jettison motor nozzles are individually canted to produce a thrust offset that moves the unused escape system laterally away from the launch vehicle's flight path as it continues along its nominal ascent trajectory. The lateral trajectory is further enhanced by a radial center of gravity (cg) offset of the fairing. The jettison motors burn out in approximately three seconds, after which the escape vehicle reenters the atmosphere and tumbles during descent. The fairing is not recovered. 


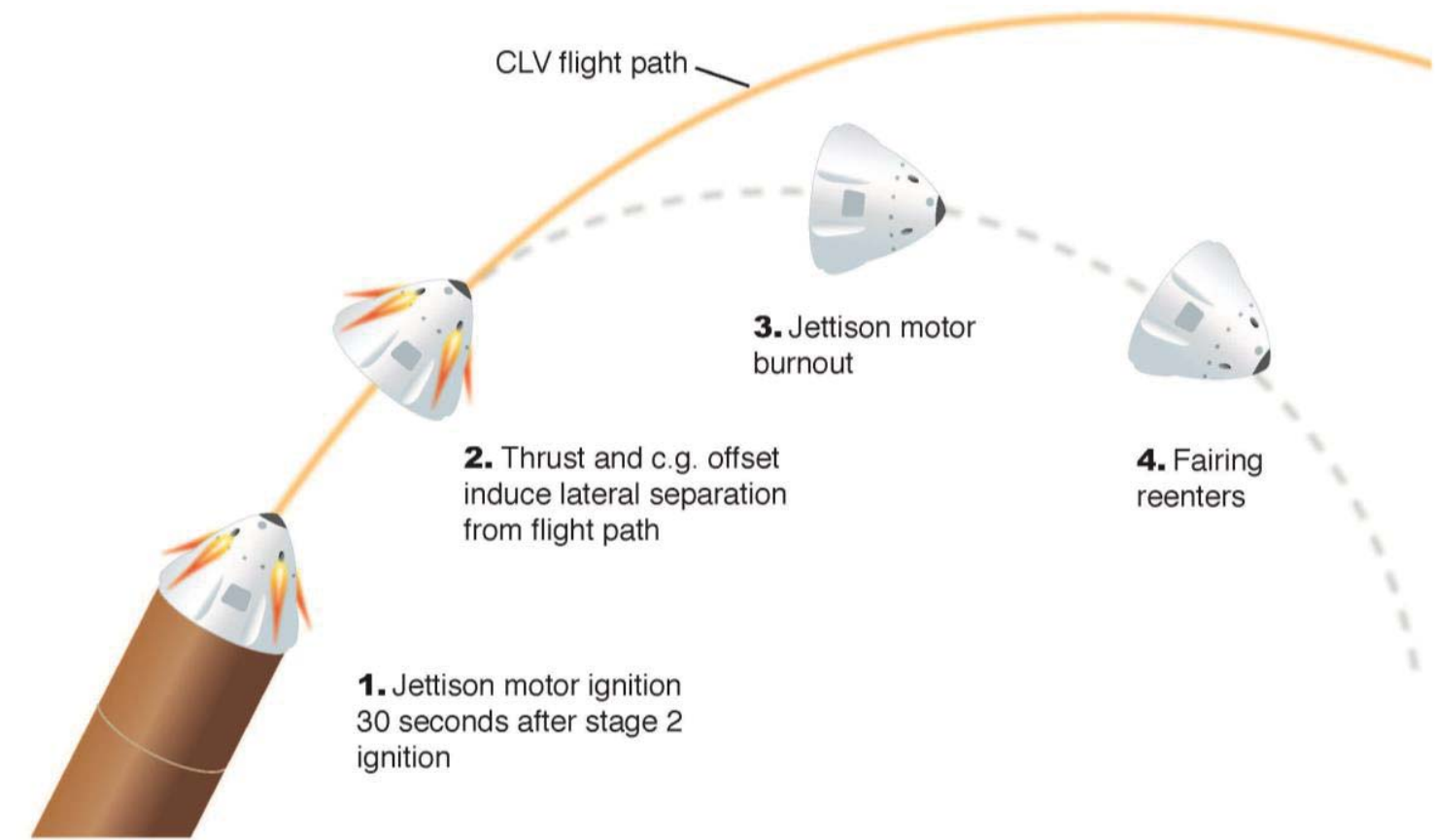

Figure 6. OS-1 \& OS-2 concept of operations for jettison of escape system during a nominal launch.

\section{Solid Rocket Escape Motors}

The OS-1 design discussed in this paper includes six solid rocket escape motors equally spaced 60 deg apart around the circumference of the fairing (Fig. 3) and canted 30 deg from the escape vehicle axial, or longitudinal axis, to reduce plume impingement effects (Fig 7). As described in the ConOps discussion, the crew escape trajectory is initiated when all six motors simultaneously ignite regardless of the escape regime (pad/low-altitude, mid-altitude or high-altitude). Alternate allpropulsive escape system concepts were evaluated in which pad escapes used a staged ignition sequence to alleviate unnecessarily high crew accelerations, but those results were not included in this paper.

A number of different factors influenced the design of the escape motor thrust profile. The peak thrust was driven by the separation distance requirement during a transonic escape when suction drag inhibiting separation is highest, while the total impulse was established by the altitude/downrange requirement to ensure a safe water landing for an off-the-pad escape. In addition, proper shaping of the thrust tail off can significantly improve the ability of the system to accommodate

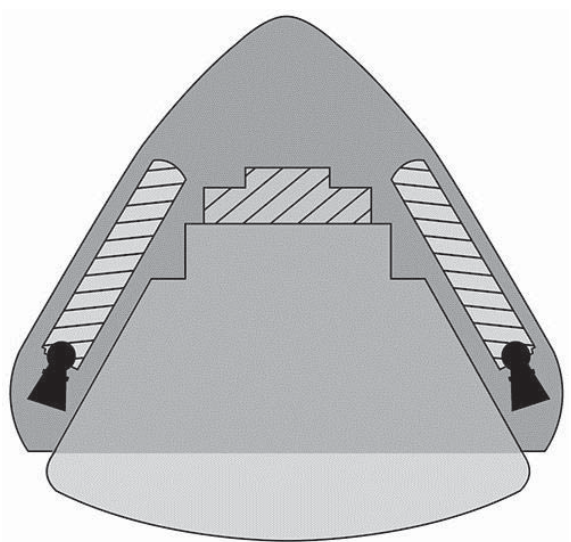

Figure 7. OS-1 side-view schematic showing tilt of escape motors. thrust dispersions arising from motor-to-motor differences in bulk propellant temperature and propellant burn rate (due to small differences in propellant mix composition during manufacturing). By extending the time of the thrust tail off to avoid step-like thrust profiles, differences in the thrust of each motor due to variations in burn rates can be decreased, thus reducing the magnitude of unwanted disturbance torques that must be compensated for by the TVC system during the critical boost and maneuvering phase of the escape trajectory.

Figure 8 shows the evolution of normalized thrust profiles that were considered during the concept exploration phase of the study. The first thrust profile maintained high thrust for as long as possible to ensure rapid separation but had a rapid thrust tail off. This thrust profile was rejected because burn rate variations produced large disturbance torques due to some motors experiencing the rapid tail off before others. The second profile decreased the time of the high thrust segment and included a much more gradual thrust tail off. Analysis showed that the shorter highthrust segment was still sufficient to meet performance requirements and that the longer tail off significantly reduced the magnitude of thrust dispersions thus reducing the effect of asymmetric burnout. Thrust Profile 2 was used for all 
of the trajectory results shown in this paper. A later iteration (Thrust Profile 3) was shown to reduce the effect of thrust dispersions even further by smoothing the inflection points on Thrust Profile 2.

One additional thrust profile that was explored for OS-1 was a boostsustain profile. In this concept, the ACS thrusters are eliminated, and the escape motors operate for the entire duration of the escape trajectory. The boost-sustain thrust profile includes operation at two thrust levels: a highthrust segment to perform the initial escape boost and maneuvering, followed immediately by a low thrust segment where just enough thrust is provided to control the vehicle during coast and reorientation. For comparison, Fig. 8 shows a notional boostsustain thrust profile. Simulation analy-

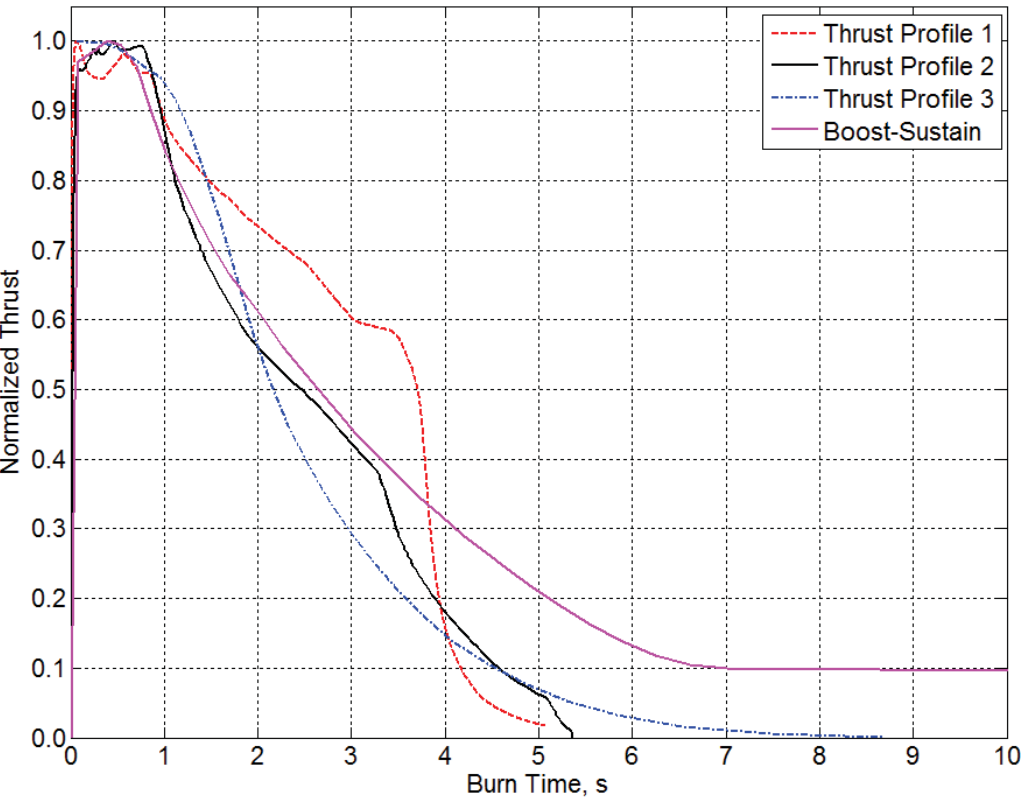

Figure 8. Evolution of escape motor thrust profiles. sis identified a number of difficulties with using this thrust profile to perform the OS-1 escape mission. One key problem was that control during reorientation required relatively high thrust levels during the sustain segment, which, in turn, significantly increased the amount of escape motor propellant. Moreover, higher sustained thrust increased the dynamic pressure at reorientation, further exacerbating the control authority problem. Finally, burn rate dispersions during the transition from high to low thrust may cause disturbances that are too large for the sustain TVC to control. For these reasons, the concept was not pursued.

\section{Escape Motor Thrust Vector Control}

The solid rocket escape motors included a thrust vector control system for stability and three-axis control during the escape boost. This initial segment of the escape trajectory requires a significant amount of control authority in order to 1) damp out initial dispersions due to the launch vehicle failure; 2) perform a pitch over maneuver to steer the vehicle down range from the pad or away from the vehicle flight path in an ascent failure; 3) begin to maneuver the vehicle back to a coasting attitude after the initial pitch over; and 4) compensate for disturbances due to winds, aerodynamics, and asymmetric thrust dispersions.

For this study, each escape motor was assumed to have a hydraulically actuated nozzle that could be individually deflected up to $15 \mathrm{deg}$ in any direction at a slew rate of $200 \mathrm{deg} / \mathrm{s}$. The nozzles were not permitted to be deflected inward (i.e., thrust vector was constrained to always be $30 \mathrm{deg}$ or more from the longitudinal axis) to minimize plume impingement on the sides of the fairing. To accommodate this constraint, opposite motors (located 180 deg apart) were operated in pairs, such that when one motor reached the 30 deg inward deflection limit, it was held in place and the opposite motor was then deflected outward.

In conventional rocket applications where deflectable nozzles are located at the end of a long, slender launch vehicle, thrust control moments are generated by lateral thrust forces from deflecting the nozzle acting on a long moment arm from the nozzle action point to the vehicle c.g. However, with the short, blunt OS-1 configuration, this axial moment arm is much shorter because there is little axial separation between the escape motor nozzles and the vehicle c.g. Instead, most of the OS-1 TVC system thrust moment is generated from the combination of the radial separation between two motors in a given motor pair and their thrust differential in the axial direction (which results when they have different nozzle deflections). Figure 9 shows a schematic illustrating this idea. In addition to being dependent on the difference in nozzle deflections between opposite motors, the thrust moments that are generated are also influenced by the total deflection of the nozzles. That is, a larger thrust moment is generated if opposite motors have deflections of 45 and 30 deg, respectively, than if they were deflected at 15 and 0 deg, even though both have the same 15 deg differential. Thus, while the 30 deg cant angle of the escape motors desired for plume impingement avoidance produces cosine losses that reduce performance, it is beneficial and even necessary for ensuring adequate control authority of the OS-1 TVC system. 
One final point to be made about the TVC control authority is that it is proportional to thrust. Consequently, after the initial high thrust segment, TVC control authority decays, eventually falling below useful levels as the escape motors burn out. For this reason, it is necessary for the ACS thrusters to be activated during the escape motor thrust tail off to maintain control authority. Figure 10 shows a representative time history of TVC pitch control authority during a pad abort. The level of pitch control available from the ACS thrusters is shown for reference. The figure illustrates the need for large maneuvers to be performed in the first 2 to $3 \mathrm{sec}$ when TVC control authority is highest.

\section{Liquid Attitude Control System Thrusters}

The OS-1 design includes eight liquid attitude control system engines using hypergolic bipropellants of hydrazine (MMH) and nitrogen tetroxide

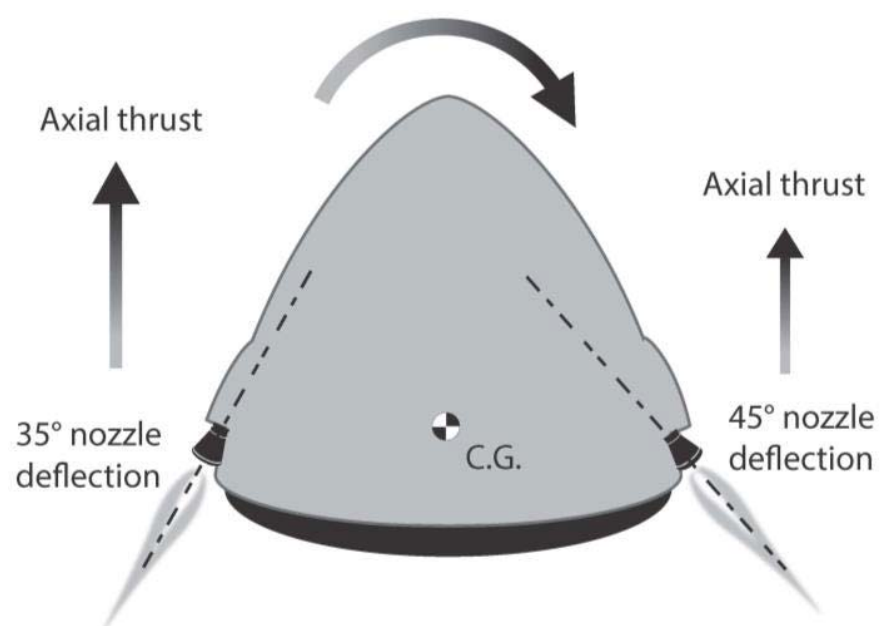

Figure 9. Schematic illustrating operation of escape motor TVC.

(NTO) for control during coast and reorientation phases. These thrusters become active during the escape motor thrust tail off and continue to operate for the duration of the escape trajectory, until the fairing is jettisoned.

The eight ACS thrusters are positioned around the circumference of the fairing in the arrangement shown in Fig. 3. Each thruster is canted outward 15 deg from the longitudinal axis (to avoid plume impingement). The thrusters can be turned on and off in various combinations in order to produce pitch and yaw control moments and have a minimum on/off time of $50 \mathrm{~ms}$. For typical operation during an escape trajectory, each thruster is cycled on and off numerous times as the control moment requirements vary, and varying amounts of pitch and yaw moments can be generated given the assumed motor layout of the eight thrusters. More pitch torque capability is available than yaw since most maneuvering is done in the pitch plane. Note that it is possible to orient the thrusters on the fairing with a small sideways cant angle to provide limited roll control capability, although that was not done in this study.

When sizing the attitude control system, the CM radial c.g. offset had to be considered. The CM c.g is designed to be offset in the radial direction by up to 6 inches in order to achieve a desired angle of attack and lift to drag ratio (L/D) during reentry. Consequently, the combined CM and escape system c.g. has an $~ 3.6$ inch radial offset because of the large radial c.g. offset of the CM. This radial c.g. offset affects the aerodynamic pitching moment during escape, increasing the control moment required to maintain stability during the nose-forward coast segment of flight. Figure 11 shows this effect where the aerodynamic pitching moment about the combined c.g. is plotted as a function of angle of attack at conditions corresponding to the instant the ACS motors are activated during a representative maximum dynamic pressure escape trajectory. Also plotted is the maximum pitch control torque that can be generated for a six-thruster and eight-thruster ACS configuration. The CM with the escape system attached is aerodynamically unstable in pitch, and the control moment capability of the eight-thruster attitude control system is incapable of overcoming

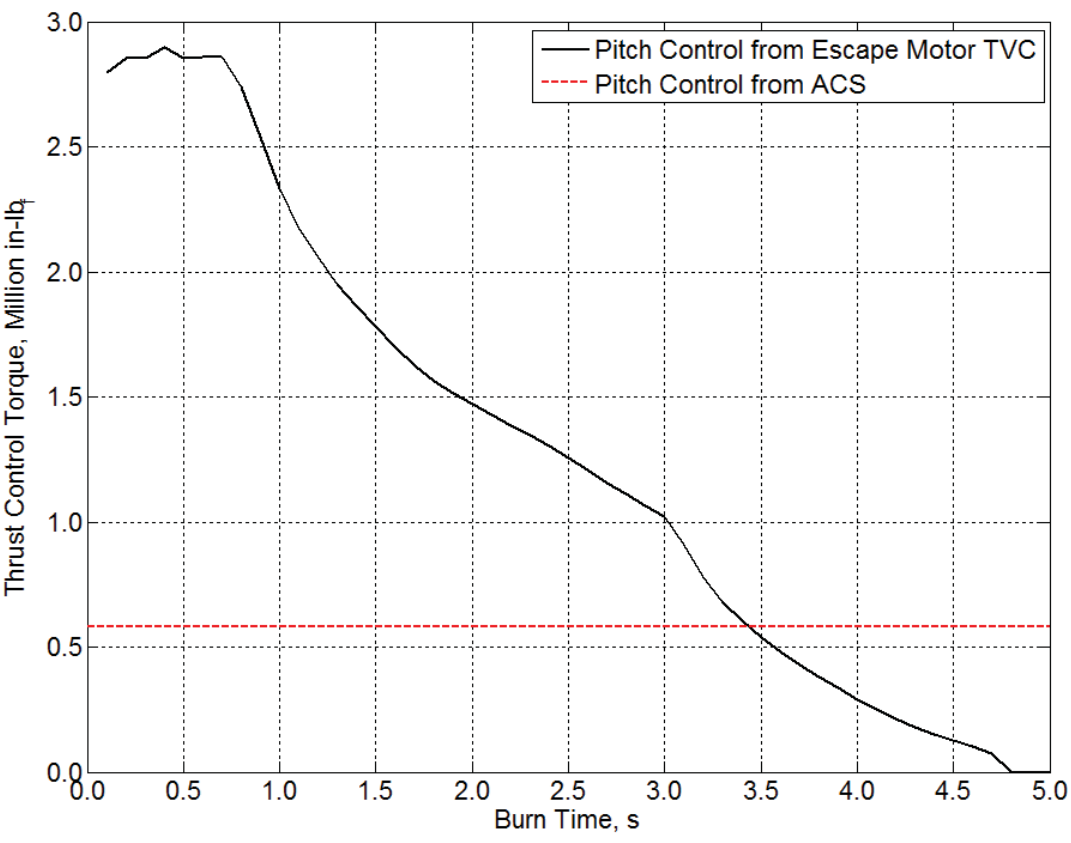

Figure 10. A representative time history of TVC pitch control authority during a pad abort. 
the aerodynamic moment at 0 deg angle of attack. Ballast was added to the escape system fairing in order to shift the c.g. toward the centerline and reduce the aerodynamic moment to within the ACS capability. Figure 11 also shows the effect of adding $1,000 \mathrm{lbm}$ of ballast to one side of the escape fairing in order to shift the radial c.g. approximately 3 inches towards the vehicle centerline. With the added ballast, the aerodynamic pitching moment is shifted downward and remains well within the control moment capability of the ACS at the low angles of attack required for coasting flight. As a result of this analysis, $1,000 \mathrm{lbm}$ of ballast was included in the OS-1 design to improve control margins; however, further analysis has suggested that it may be possible to achieve acceptable control performance with less ballast, but additional study is needed.

\section{Solid Rocket Jettison Motors}

Three solid rocket booster separation motors used for the Space Shuttle solid rocket motor separation were used as jettison motors in the OS-1 configuration. Each jettison motor had a peak vacuum thrust of roughly 23,000 lbf. The overall burn time including tail off was $\sim 3 \mathrm{~s}$, but the peak thrust duration was less than $1 \mathrm{~s}$. The jettison motors served two purposes: 1) removal of the unused escape system during a nominal (no failure) launch; and 2) removal of an empty (i.e., fuel-depleted) escape system fairing from the CM at the end of an escape trajectory after the CM has been safely separated from the launch vehicle. For the latter case of a jettison performed at the end of an escape, the fairing also removes the docking system that is attached to the CM, ensuring that the CM is in its entry configuration.

All three of the jettison motor nozzles must be canted at least 45 deg from the longitudinal axis to avoid plume impingement on the side of the fairing. In addition, each cant angle can be further adjusted such that the net thrust vector from the combined three motors can be slightly offset from axial. Offsetting the net thrust vector creates a thrust moment during the jettison motor burn that acts to rotate the fairing as it pulls away from the launch vehicle or the CM. The thrust offset must be carefully set so that enough rotation occurs to sufficiently rotate the fairing and direct it away from the flight path, but not so much rotation as to cause recontact while the fairing pulls away during the early part of the jettison. Proper adjustment of the jettison motor cant angles is particularly important given the large radial c.g. offset due to the addition of ballast for improving control margins (see previous section).

Prior to jettison, the ACS motors are turned off to avoid attitude excursions during separation. The idea of eliminating the jettison motors and using the ACS thrusters to perform the jettison function was assessed during concept development, but separation performance was found to be inadequate because of their relatively low thrust levels.

\section{OS-2: Escape Vehicle Concept with Passively Stable Coast}

The OS-2 vehicle concept shown in Fig. 2 is similar to the actively controlled OS-1 configuration, using the same modified Sears-Haack-shaped aerodynamic/structural fairing and arrangement of six solid rocket escape motors. As with OS-1, the escape motors are equipped with TVC to actively control the vehicle during the initial boost segment of the escape trajectory. However, OS-2 eliminates the attitude control system, and instead, just before escape motor burnout, deploys aerodynamic grid fins for passive aerodynamic stability during nose-forward coasting flight. The grid fins will be jettisoned when reorientation to a heat shield first attitude is commenced. Reorientation is induced by mortar-deployed drogue parachutes that are mounted near the nose of the fairing. The OS-2 configuration also includes fixed solid rocket jettison motors to separate the fairing from the CM during an escape as well as remove the unused escape system from the launch vehicle during a nominal ascent. Key elements of the OS-2 de- 
sign, including the use of fins (conventional fins, not grid fins) for aerodynamically stable noseforward flight, and passive reorientation with drogue parachutes, were demonstrated by the NASA Engineering \& Safety Center (NESC) in a successful escape-from-the-launch-pad flight test at the NASA Wallops Flight Facility on July 8, 2009. ${ }^{4}$

Figure 12 shows the vehicle layout and overall dimensions of the concept that was studied in this paper.

\section{Concept of Operations}

The concept of operations for the OS-2 crew escape system can be classified into the same four operational procedures that were described for OS1: pad/low-altitude escape, mid-altitude escape, high-altitude escape, fairing jettison during a nominal launch.

During a nominal launch, the solid rocket escape motor nozzles, solid rocket jettison motor nozzles, and reorientation drogue mortars are covered by panels that maintain the clean aerodynamic shape of the fairing. The grid fins are folded up and stowed conformal to the fairing body. Upon initiation of a crew escape, the panels are removed and the escape motor nozzles are deflected outward to their initial thrusting orientation. The grid fins remain stowed until they are needed for stability, at which point the hinge joint connecting them to the fairing is released, and they fold downward so that their surface faces the flow as shown in Fig. 2. Once the panels are removed and nozzles are aligned, the escape motors are ignited, and the escape trajectory is initiated.
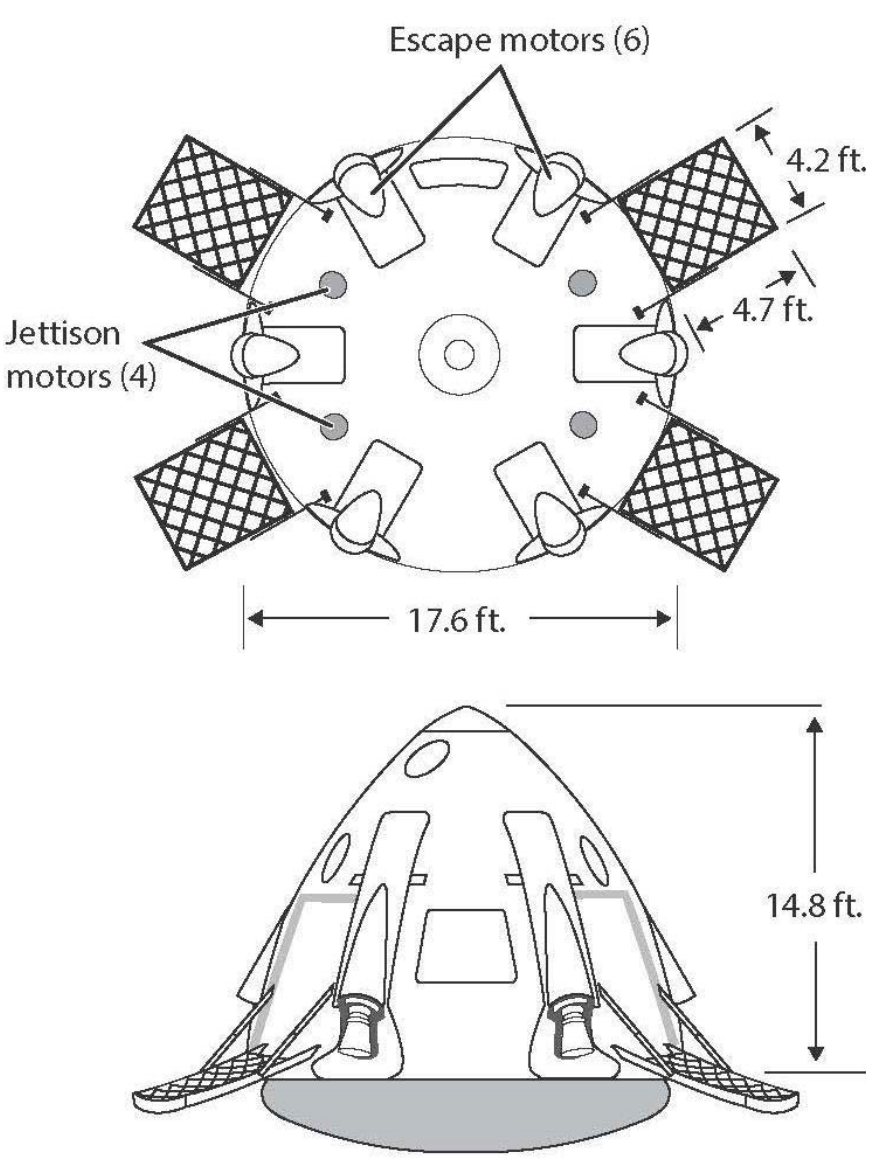

Figure 12. The overall dimensions and configuration layout of the OS-2 concept.

The same pre-ignition sequence is followed for each type of escape.

Figure 13 shows the ConOps for a pad/low-altitude escape beginning at escape motor ignition. The six escape motors ignite and a controlled pitch-over maneuver is performed using TVC to place the escape vehicle on a trajectory that maximizes downrange from the shoreline and gains sufficient altitude to ensure a safe parachute landing in the water. As the escape motor thrust begins to tail off, and the TVC control authority diminishes below useful levels, the fin attachment joints are released, and the grid fins fold away from the body and extend into the flow. The grid fins provide aerodynamic stability throughout escape motor burnout and are sized to adequately compensate for any thrust dispersions. After escape motor burnout, the escape vehicle is passively stable with the grid fins deployed and remains near its trim angle of attack for the duration of the coast phase. Near apogee, the fin attach joints are released, and the grid fins are jettisoned while the drogue mortars are fired to deploy parachutes and initiate reorientation. As the forward-mounted drogue parachutes inflate, they reorient the craft to a stable heat shield forward orientation. The escape vehicle coasts under the parachutes until body rates are sufficiently damped. The duration of coast under reorientation drogues must be limited in order to remain above the minimum allowable altitude for main parachute deployment. Once the body rates are damped or the minimum altitude is reached, the reorientation parachutes are released and the small solid-rocket jettison motors are ignited to remove the escape system fairing from the CM. Once the escape system is removed, landing parachutes are immediately deployed to facilitate a water landing. 


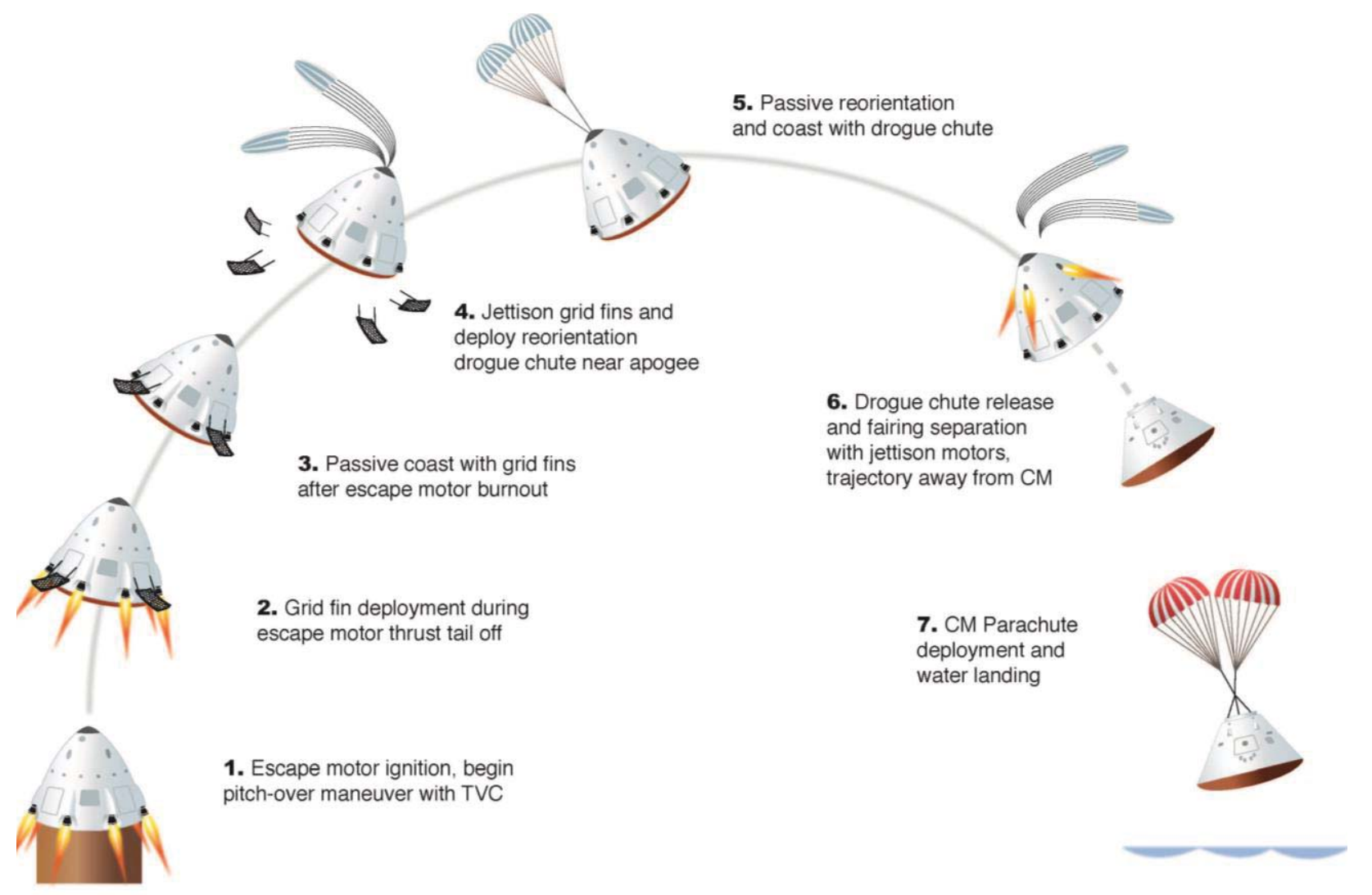

Figure 13. OS-2 concept of operations for a pad and low altitude escape.

The OS-2 ConOps for escape from mid-altitude launch vehicle failures is nearly the same as that for pad/lowaltitude escapes. One difference is that reorientation generally occurs later in the escape trajectory to provide time for the dynamic pressure to decay so that parachute load limits are not exceeded when the reorientation drogues are deployed. For pad/low-altitude escapes, dynamic pressure levels are lower and reorientation timing is driven by the altitude/downrange requirements. Another difference is that the duration of coast under the reorientation drogues is typically longer for mid-altitude escapes because more time is needed to damp attitude oscillations induced by reorientation, which are larger than for pad/low-altitude escapes due to the higher dynamic pressure levels.

The OS-2 high-altitude escape ConOps (Fig. 14) becomes applicable when dynamic pressure levels drop to the point where grid fins are ineffective (i.e., aerodynamic forces are small, but not necessarily negligible). Consequently, in this regime, reorientation must be performed by the CM's RCS thrusters. 


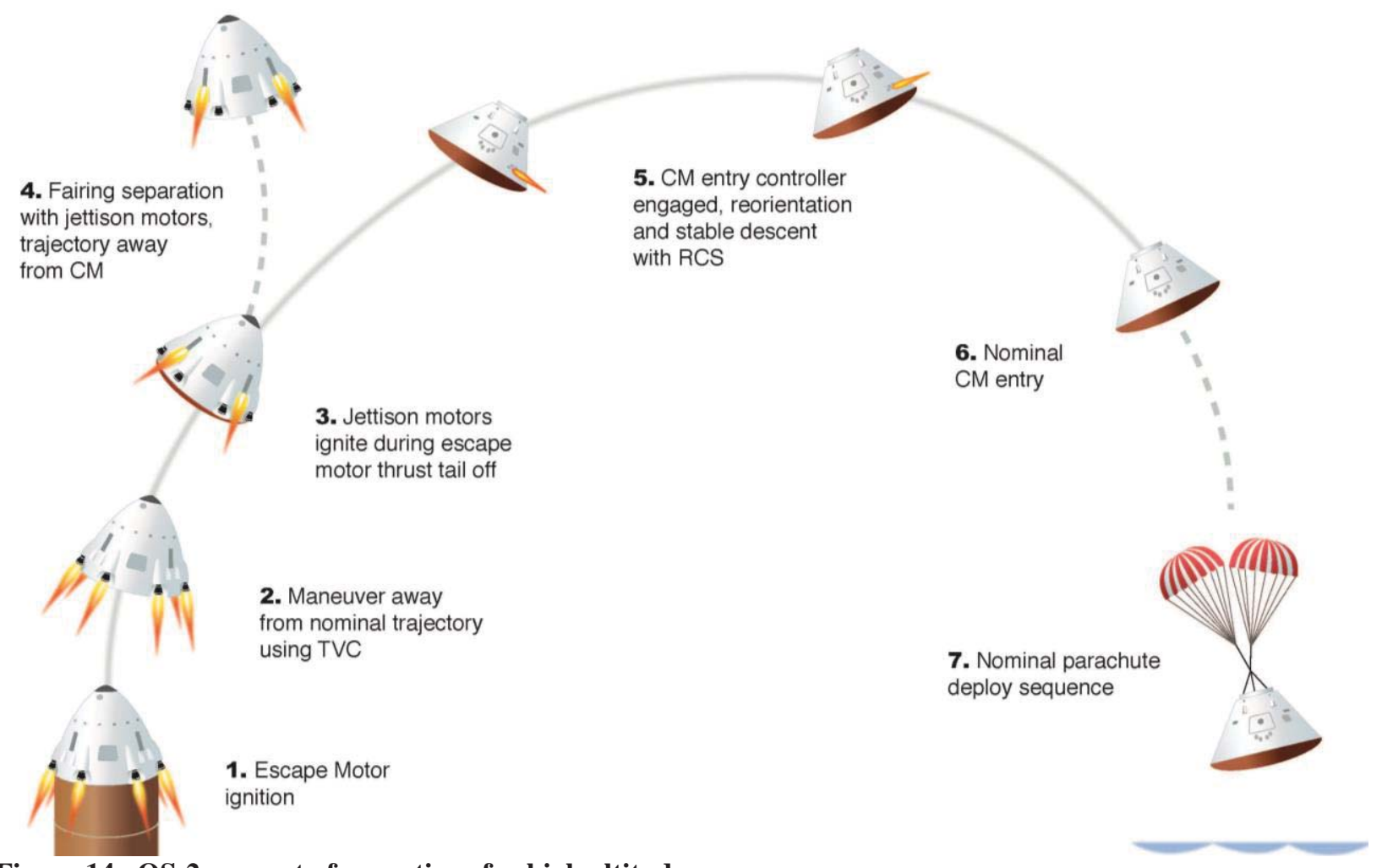

Figure 14. OS-2 concept of operations for high altitude escape.

As before, the escape trajectory is initiated when escape motors ignite and the CM is maneuvered away from the projected launch vehicle flight path. To avoid oscillations due to thrust dispersions, the escape fairing is jettisoned during the escape motor thrust tail off, with the fixed jettison motors individually canted to separate the fairing and place it on a trajectory taking it away from the CM. Next, RCS is used to reorient the CM to a heat shield forward attitude at which point it performs a nominal entry. Once the CM descends to the parachute deployment altitude, a nominal parachute descent sequence is followed.

The crew escape system jettison during a nominal (no failure) launch follows the same ConOps as OS-1 (Fig. 6).

\section{Grid Fins}

Deployable grid fins were added near the base of the OS-2 configuration to provide aerodynamic stability during the nose-forward coast segment. Grid fins provide a number of benefits over conventional fins and have been the subject of numerous research studies. ${ }^{5,6}$ For an escape vehicle, grid fins provide a number of benefits over conventional fins and are used on the Soyuz Launch Escape System. One significant benefit is their ability to be folded against the vehicle's body when stowed to reduce aerodynamic interference during a nominal launch.

On the OS-2 configuration the attachment joints for the grid fins were placed as far aft as packaging constraints would allow (Fig. 12), thereby placing the center-of-pressure (c.p.) of the grid fins as far behind the vehicle c.g. as possible. To further enhance stability, the grid fins were swept back 19 deg, which moved the c.p. of the grid fins further aft, nearly in line with the base of the fairing. The 19 deg sweep angle was selected because there was little wind tunnel data available for grid fins with larger sweep angles. Moreover, too much sweep is undesirable because it reduces the effective area of the grid fins by decreasing the amount of fluid volume that can pass through them.

The grid fins were sized to provide a static margin of $5 \%$ of the aerodynamic reference length (the diameter of the heat shield), which was determined through simulation studies to result in a suitable level of aerodynamic stability that provided adequate coasting performance. With less stability, the vehicle became marginally stable and prone to large attitude oscillations when perturbed. The effective area of the grid fins, accounting for the sweep angle was approximately 2,700 sq. in.

\section{Reorientation Drogue Parachute}

Two mortar-fired drogue parachutes provide a passive reorientation capability to the OS-2 escape vehicle. The variable porosity conical ribbon parachutes had a 27.6 -ft reference diameter and were the same as those used in the 2009 MLAS flight test. Results from that pad escape flight test showed that it could take up to 20 sec for body rates to damp out after reorientation drogue deployment. 


\section{Fairing Jettison}

A propulsive jettison of the OS-2 fairing at the end of the escape trajectory is conducted in a similar manner as OS-1, using Shuttle-heritage solid rocket booster separation motors. For OS-2, the jettison motors had to be located closer to the nose than for OS-1 to make room for the grid fins. Because of packaging constraints, they are recessed further into the fairing and are canted at least 55 deg from the longitudinal axis to maintain a clean aerodynamic shape. Because of the increased cosine losses associated with the larger cant angle, OS-2 required four jettison motors instead of three like OS-1. Each individual jettison motor nozzle was canted by a varying amount (at least 55 deg from the longitudinal axis) to adjust the orientation of the net thrust vector to meet separation performance and near-field clearance requirements.

During concept development an option was considered to use the reorientation drogue to perform the jettison function by allowing it to pull the escape fairing off of the CM at the end of an escape. However, this option was not pursued because it did not provide sufficient lateral clearance. Because much of the vehicle's horizontal velocity is lost during the reorientation and subsequent coast under the drogue parachutes, the vehicle will be on a nearly vertical trajectory at the time of jettison. By orienting the jettison motor to impart an impulse to the fairing directed away from the CM's flight path, sufficient lateral separation is induced to avoid interference with the CM during entry and parachute deployment.

\section{Performance Analysis}

\section{A. Simulation Description}

To assess the feasibility and controllability of different escape vehicle concepts, a multi-body simulation of the entire escape trajectory sequence was developed using the Program to Optimize Simulated Trajectories II (POST2). ${ }^{7}$ The POST2 simulation modeled the 6DOF motion of the MLAS escape system, Orion Crew Module and launch vehicle from escape motor ignition until fairing jettison.

\section{Aerodynamics}

A comprehensive 6DOF aerodynamic force and moment database of the basic OS-1 configuration was constructed from wind tunnel data and computational fluid dynamic calculations. This database was also used in OS-2 simulations when grid fins were not deployed. The database included data from Mach 0.3 to 4.0 over a full 0 deg (nose-first) to 180 deg (heat shield first) angle of attack range.

A separate OS-2 database was developed that included grid fin increments for angles of attack up to 30 deg over the same Mach range. ${ }^{8}$ These increments were based on wind tunnel results and were used whenever grid fins were deployed.

Finally, a separation axial force increment based on Apollo data was used to model the suction drag effect at the beginning of the escape trajectory. ${ }^{9}$ This added drag force inhibits separation as the escape vehicle separates from the launch vehicle in the first moments of the escape motor burn. The highest levels of suction drag occur at transonic conditions, and the effect decays as the separation distance between the escape vehicle and the launch vehicle increases and is assumed to be zero when the escape vehicle is three diameters away. This effect was included to ensure that the escape motors were adequately sized to meet separation distance requirements.

\section{Mass Properties}

Table 3 provides the weights of each major subsystem for both the OS-1 and OS-2 crew escape system concepts. In addition, the simulation also included mass properties for a representative CM capsule that was assumed to weigh $\sim 21,400 \mathrm{lbm}$.

Table 3. The weights of each major subsystem for both the OS-1 and OS-2 crew escape system concepts.

\begin{tabular}{|c|c|c|}
\hline Description & $\begin{array}{c}\text { OS-1 } \\
\text { (All-propulsive) }\end{array}$ & $\begin{array}{c}\text { OS-2 } \\
\text { (Passively } \\
\text { Stable Coast) }\end{array}$ \\
\hline MLAS & 15,102 & $\mathbf{1 4 , 9 9 6}$ \\
\hline Structure & $\mathbf{3 , 3 7 6}$ & $\mathbf{3 , 7 7 4}$ \\
\hline Thermal Control & $\mathbf{8 3}$ & $\mathbf{8 3}$ \\
\hline Propulsion - Escape & $\mathbf{8 , 5 8 5}$ & $\mathbf{8 , 5 8 5}$ \\
\hline Propulsion - Jettison & $\mathbf{4 8 5}$ & $\mathbf{6 4 6}$ \\
\hline Attitude Control & $\mathbf{9 7 6}$ & $\mathbf{1 , 3 1 1}$ \\
\hline ACS System & 833 & - \\
\hline Drogue Chute & - & 311 \\
\hline Grid Fins & - & 1,000 \\
\hline Structure & 143 & - \\
\hline Avionics & $\mathbf{2 2 7}$ & $\mathbf{2 2 7}$ \\
\hline Mechanisms & $\mathbf{3 7 0}$ & $\mathbf{3 7 0}$ \\
\hline CM Attach & 123 & 123 \\
\hline Hatch & 207 & 207 \\
\hline Separation & 40 & 40 \\
\hline Ballast & $\mathbf{1 , 0 0 0}$ & - \\
\hline
\end{tabular}

14

American Institute of Aeronautics and Astronautics 
The simulation modeled the effect of time-varying center-of-gravity and moments and products of inertia due to propellant depletion. Depletion of the escape motor propellant resulted in a $\sim 5.5$ inch aftward shift of the vehicle's axial c.g. over the duration of the escape motor burn, while ACS propellant depletion resulted in an additional $~ 1.0$ inch of aftward axial c.g. travel for OS-1 over the duration of ACS operation. The simulation also modeled the effect of discrete changes to the mass properties due to grid fin jettison and reorientation drogue release.

\section{Propulsion}

Detailed models of each escape vehicle propulsion system were included in the MLAS OS-1 and OS-2 6DOF simulations. In all cases, each individual motor or thruster was separately modeled to capture individual effects like TVC deflections, on/off switching of ACS thrusters, and off-nominal motor-to-motor variations that produced thrust dispersions.

\section{Flight Control}

A basic three-axis feedback control algorithm was integrated into the simulation to assess overall controllability and establish control authority requirements for propulsion system sizing. The controller followed open-loop attitude guidance commands to perform initial steering during the escape motor boost for both OS-1 and OS-2. In addition, it was also used during ACS thruster operation for OS-1to maintain control during coasting segments and to perform the reorientation maneuver.

The control algorithm included mixing logic that determined the individual TVC deflections and ACS thruster on/off commands necessary to produce the required control moments. The mixing logic also ensured that specific propulsion system constraints were met, such as the requirement for no inward (less than $30 \mathrm{deg}$ ) escape motor TVC deflections as well as the 50 ms minimum ACS thruster on/off time limit.

A final function performed by the control algorithm was a smooth transition from escape motor TVC to ACS thruster operation.

\section{Reorientation Parachute}

A basic parachute model was included in the OS-2 simulation that modeled the inflation of both reorientation drogues connected to the forward attach point. The model was validated using flight data from the 2009 MLAS flight test. ${ }^{4}$

\section{Atmosphere and Winds}

Atmosphere and winds were modeled using the Kennedy Space Center range reference atmosphere included in Version 1.4 of the 2007 Global Reference Atmospheric Model (Gram 2007). ${ }^{10}$ The GRAM 2007 model was also used to generate dispersed wind and atmosphere profiles for off-nominal trajectory simulation.

\section{B. Nominal Escape Trajectory Performance}

Multiple nominal (undispersed) trajectory simulations were performed at the four flight conditions listed in Table 1 for both escape system concepts to ensure that the mission escape requirements listed in Table 2 could be met. The effect of dispersions and uncertainties was considered and is discussed in the next section.

Trajectory results for a simulated off-the-pad escape are shown for OS-1 in Figs. 15-18. For a nominal pad escape trajectory, the vehicle reaches an apogee altitude of 6,700 feet, a peak Mach number just over 0.6 , and a maximum dynamic pressure level of 550 psf at $\sim 3.5 \mathrm{sec}$
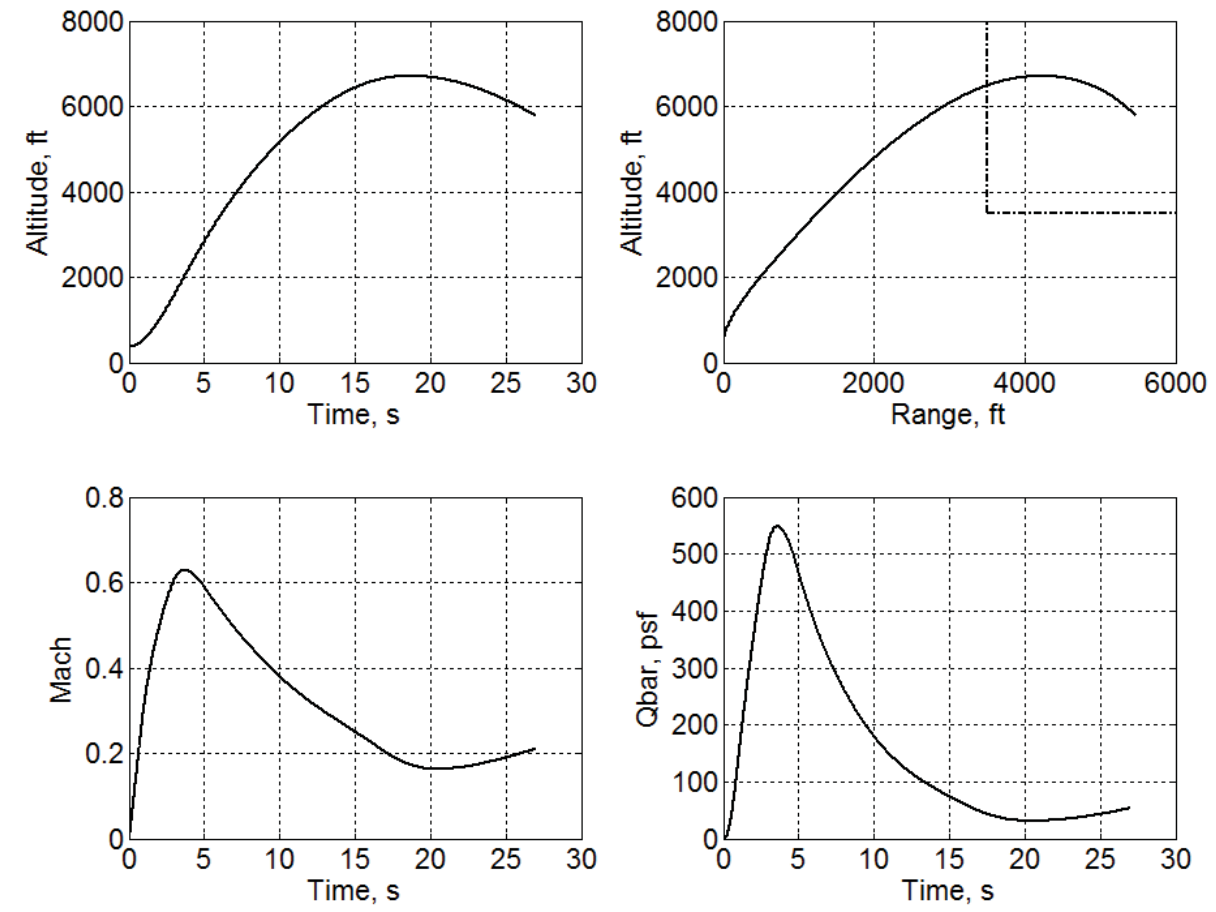

Figure 15. OS-1 trajectory results for a simulated off-the-pad escape.

15

American Institute of Aeronautics and Astronautics 
into the escape motor burn. For this case, the altitude and downrange requirement constraints (shown as a dashed box in Fig. 15) were satisfied with margin.

Acceleration levels exceeding $12 \mathrm{~g}$ are encountered for $\sim 1 \mathrm{sec}$ during the escape motor burn (not shown) but quickly diminish as the escape motors burn out. Figure 16 shows the aerodynamic angles during the escape trajectory. An angle of attack of $~ 15$ degrees is attained during the first two seconds of the escape motor burn when the vehicle is performing its pitch over maneuver to meet the altitude and downrange requirement. The rate and amount of pitch over is constrained by peak load constraints as well as thrust vector control rate and deflection limits. For this
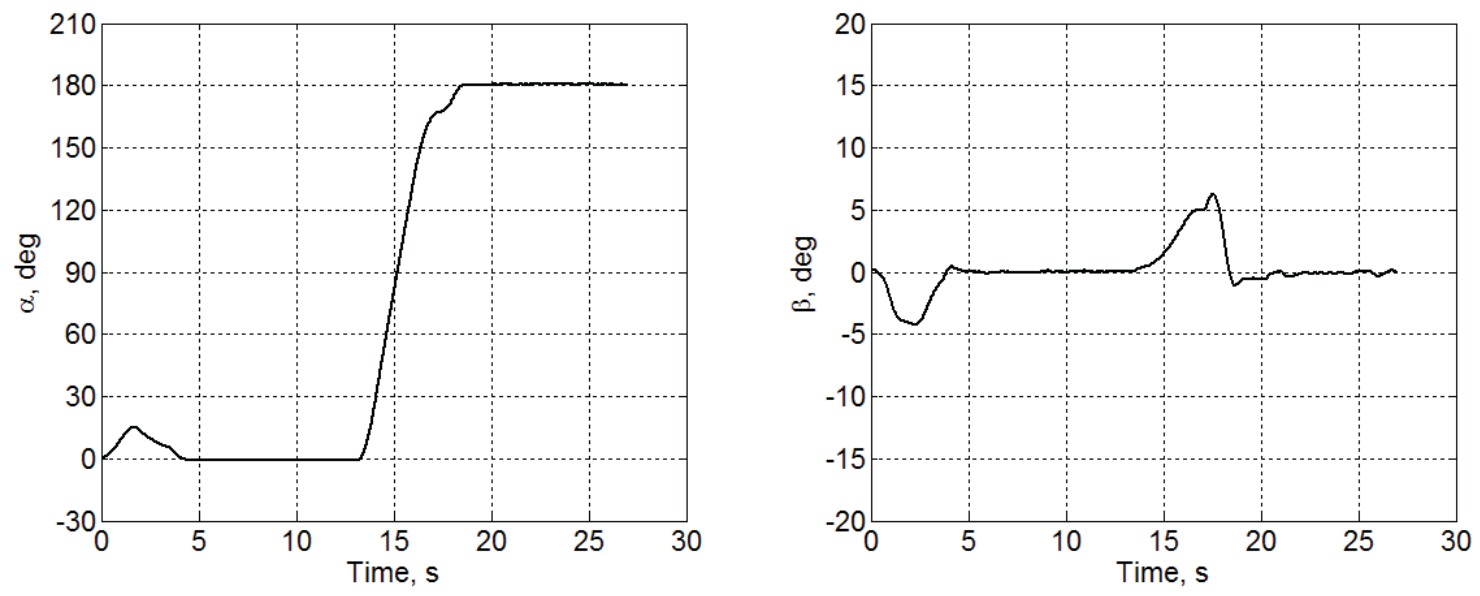

Figure 16. OS-1 trajectory results for a simulated off-the-pad escape.
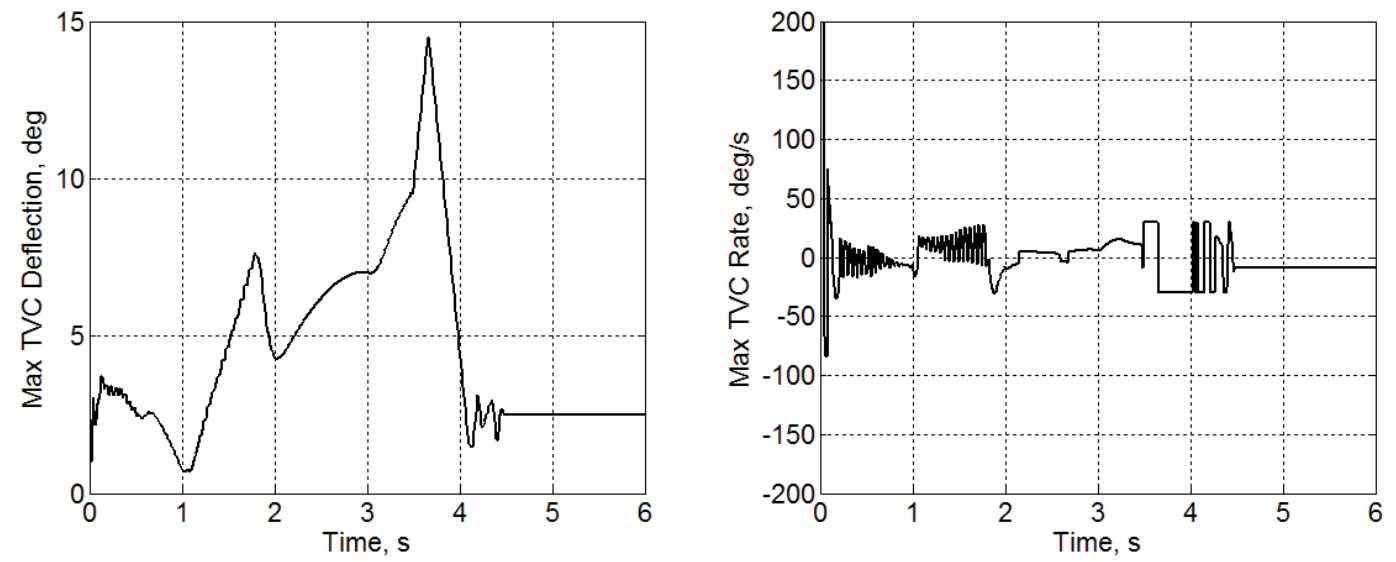

Figure 17. OS-1 trajectory results for a simulated off-the-pad escape.
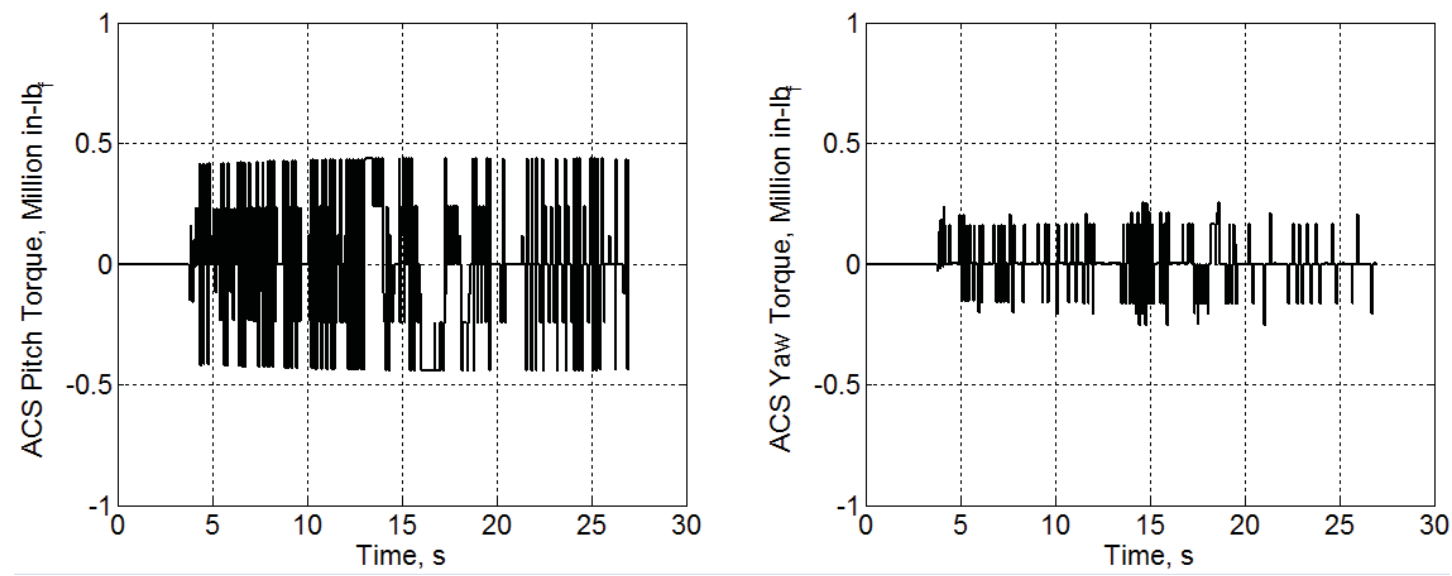

Figure 18. OS-1 trajectory results for a simulated off-the-pad escape.

American Institute of Aeronautics and Astronautics 
study, Q-Alpha-Total (product of dynamic pressure and total angle of attack) was used as a load indicator. The QAlpha-Total indicator peaked at 5,000 psf-deg during the pitch over, well below the 10,000 psf-deg limit.

Reorientation from a nose-first to heat-shield-first attitude (0 to 180 deg angle of attack) is initiated 13 sec after escape motor ignition, when the vehicle is approaching apogee and the dynamic pressure drops below 100 psf. The reorientation maneuver is performed with the ACS thrusters and takes $\sim 5 \mathrm{sec}$ to complete. Throughout the maneuver, angle of attack and sideslip excursions remain small and attitude rates are quickly damped prior to fairing jettison, which occurs at
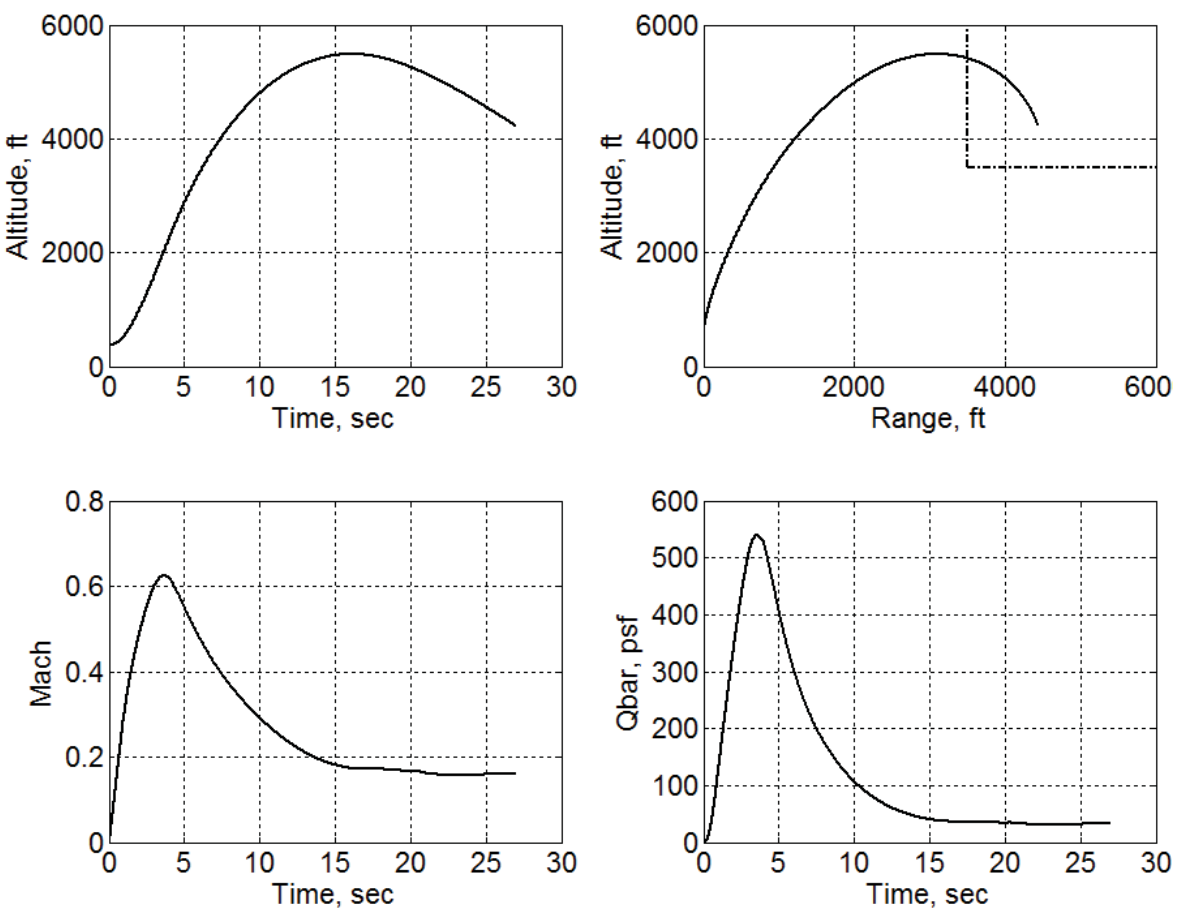

Figure 19. OS-2 trajectory results for an OS-2 off-the-pad escape. $27 \mathrm{sec}$.

Figure 17 shows thrust vector control system performance for this case. TVC deflections are kept below 10 deg for the first 3.5 seconds of the trajectory. At this point the escape motor thrust has dropped to below $20 \%$ of its maximum level and is continuing to decrease rapidly as motor burnout approaches. A linear transition to ACS control is initiated at 3.5 seconds and by 4.5 seconds the vehicle is under full ACS control. TVC deflection rates are kept below the $200 \mathrm{deg} / \mathrm{s}$ limit with the highest rates occurring at the initiation of the pitch over maneuver.

Figure 18 shows the pitch and yaw moments generated by the ACS thrusters during the entire pad escape trajectory. Each thruster cycles on and off between 95 and 100 times, consuming approximately $68 \%$ of the available ACS propellant.

Results for an OS-2 off-the-pad escape trajectory are shown in Fig. 19 and 20. Compared to OS-1, the OS-2 vehicle reaches similar peak Mach and dynamic pressure values but a lower apogee altitude of 5,500 feet (Fig. 19). The lower peak altitude is due mainly to the increase in drag due to the deployment of the grid fins, which occurs at 3.5 sec. In addition, the large radial c.g. offset of the escape vehicle (due entirely to the radial c.g. offset of the CM)
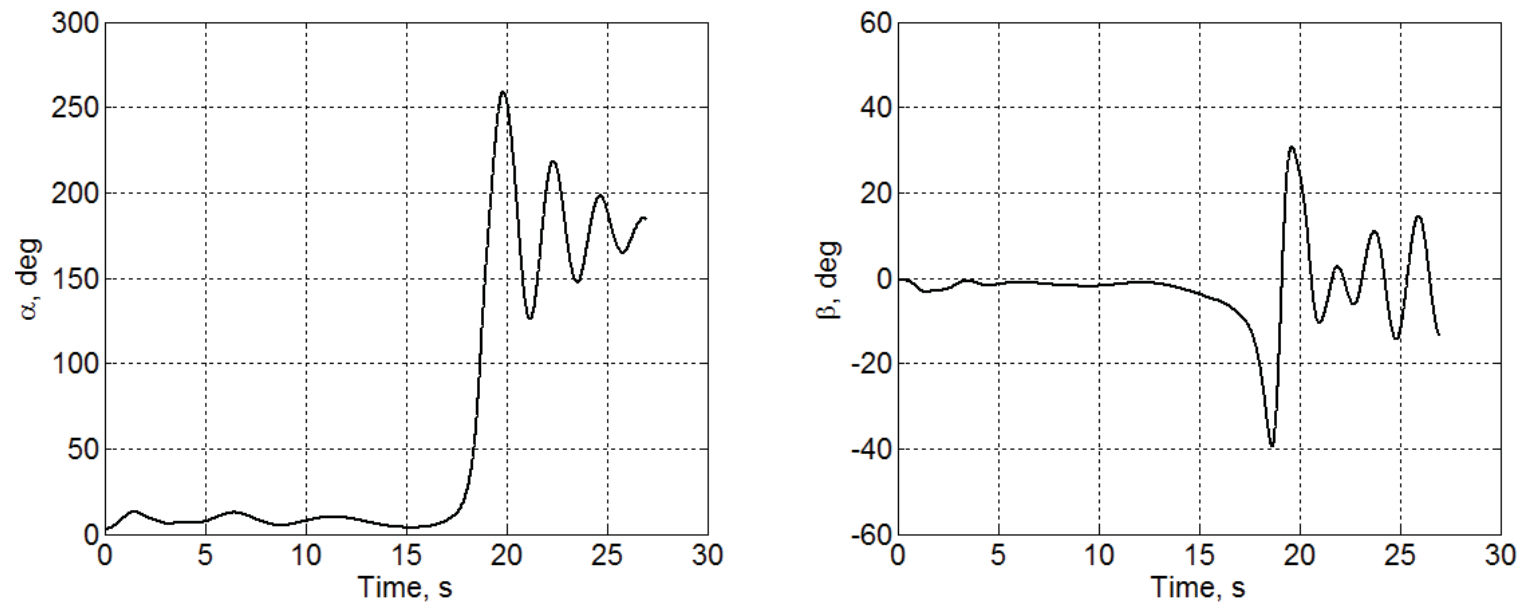

Figure 20. OS-2 trajectory results for an OS-2 off-the-pad escape.

17

American Institute of Aeronautics and Astronautics 
increases the amount of TVC deflection ( 12 deg) needed to balance moments, which further degrades performance. Despite the performance loss, the vehicle still meets the altitude/ down-range requirement.

Figure 20 shows the time history of the aerodynamic angles. After the initial pitch over, the grid fins quickly stabilize the vehicle, and it oscillates $~ 3-4$ deg about its trim attitude for the duration of the coast phase. The grid fins are jettisoned 16 seconds after escape initiation, and the reorientation drogues are deployed. The vehicle successfully reorients but experiences large attitude oscillations under the drogues. Fairing jettison occurs (and the simulation is terminated) at 27 seconds when the total angle of attack and attitude rates are within acceptable parachute deployment limits for the CM parachute system. Selected simulation results for a maximum dynamic pressure escape trajectory are shown for both OS-1 and OS-2 in Fig. 21 and 22. The escape initiates at an altitude of $\sim 44,000 \mathrm{ft}$ (not shown) near Mach 2 at a dynamic pressure close to 1,000 psf. After a small increase in Mach and dynamic pressure while the escape motors are firing (Fig. 21), both drop rapidly, and reorientation is initiated when the dynamic pressure is below 100 psf to ensure that aerodynamic forces are within ACS capability for OS-1 and to limit the opening load on the reorientation drogue for OS-2. Reorientation occurs a few seconds earlier for OS-2 because it decelerates faster during coasting flight due to the added drag of the grid fins. While both vehicles successfully reorient, OS-2 experiences significant attitude oscillations under the drogue and requires over 25 seconds of coasting to damp oscillations sufficiently for jettison to occur. During this time the added drag of the reorientation drogue quickly decelerates the OS-2 escape vehicle, removing much of its horizontal velocity and causing it to
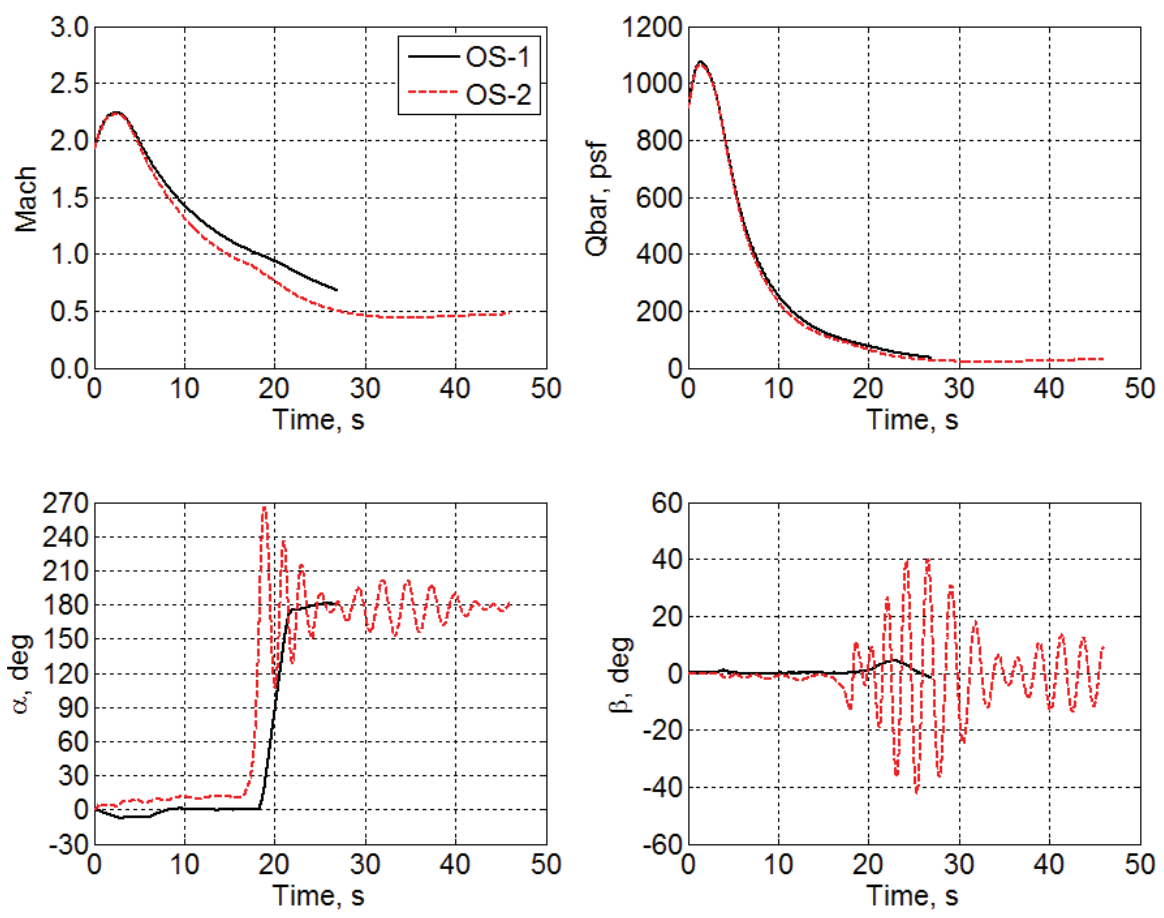

Figure 21. Comparison of OS-1 and OS-2 trajectory results for a maximum dynamic pressure escape.

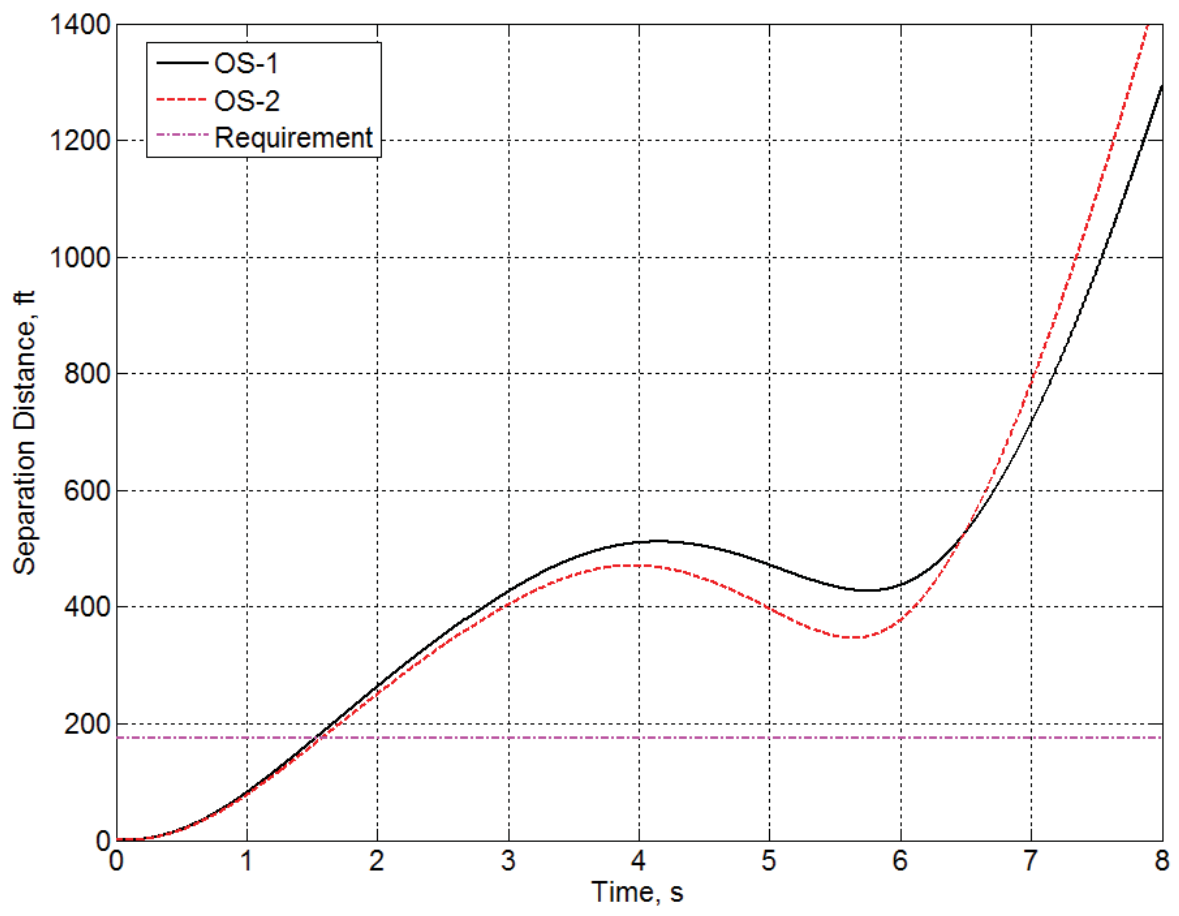

Figure 22. Comparison of separation distance between OS-1 and OS-2 for a maximum dynamic pressure escape.

18

American Institute of Aeronautics and Astronautics 
begin to descend. Conversely, the controlled reorientation performed by OS-1 requires 5 to 6 seconds to complete, and rates are almost immediately damped. In addition, the entire OS-1 escape trajectory through fairing jettison occurs as the vehicle is climbing in altitude.

\section{Off-nominal Escape Trajectory Performance}

Since the objective of this paper was to demonstrate escape vehicle concept feasibility, it was important to consider the effect of dispersions and uncertainties on overall system performance. A series of off-nominal test cases (Table 4) was run for both concepts at each of the four simulation test conditions. The test cases were selected primarily as stress cases to further evaluate the controllability of both concepts and included: different levels of aerodynamic stability due to uncertainty in center-of-pressure, differences in thrust and burn time for all escape motors due to variations in propellant temperature, large thrust dispersions on a single escape motor, significant tip-off attitude rates at initiation of the escape, high winds, and a larger radial c.g. offset

Table 4. Off-nominal test cases.

\begin{tabular}{|l|c|}
\hline \multicolumn{1}{|c|}{ Off-nominal Condition } & $\begin{array}{c}\text { No. of } \\
\text { Cases }\end{array}$ \\
\hline \hline \pm 6 -inch center of pressure shift & 2 \\
\pm 40 deg change in escape motor propellant mean bulk temperature & 2 \\
Large thrust dispersion on each escape motor & 6 \\
Large initial pitch, yaw and roll tip-off rates & 6 \\
95-percentile high wind profile & 1 \\
Increased Crew Module radial c.g. offset & 1 \\
\hline Total & 18 \\
\hline
\end{tabular}
on the CM.

Both concepts were able to meet performance metrics for all of these test cases at the four simulation test conditions (pad, transonic, maximum dynamic pressure and high altitude) that were evaluated.

Of particular concern were the thrust dispersion cases, which are an inherent risk in a design using six separate solid rocket escape motors that are fired simultaneously. Each motor can have thrust dispersions occur for a number of reasons including ignition delays, differences in propellant bulk temperature, and variations in burn rate brought on by small disparities in the propellant composition. Of these three factors, differences in burn rate cause the largest thrust discrepancies. Because each of the six escape motors will likely have slightly different dispersions, their thrust profiles will differ, and the differences will cause unexpected thrust moments.

To further investigate the robustness of the OS-1 design, a series of 500-case Monte Carlo analyses was performed assuming a different level of burn rate uncertainty. For each case in a given Monte Carlo set, the burn rate of each of the six escape motors was randomly dispersed; that is, each case was run using a different thrust profile for each of the six escape motors. Seven different Monte Carlo sets were run with three-sigma burn rate uncertainty levels ranging from $1 \%$ to $8 \%$.

Figure 23 shows the results of this analysis. First, a plot of 500 different angle of attack profiles is shown for the case with a $2 \%$ burn rate uncertainty. None of these cases tumbled, but a few of the cases had large alpha excursions
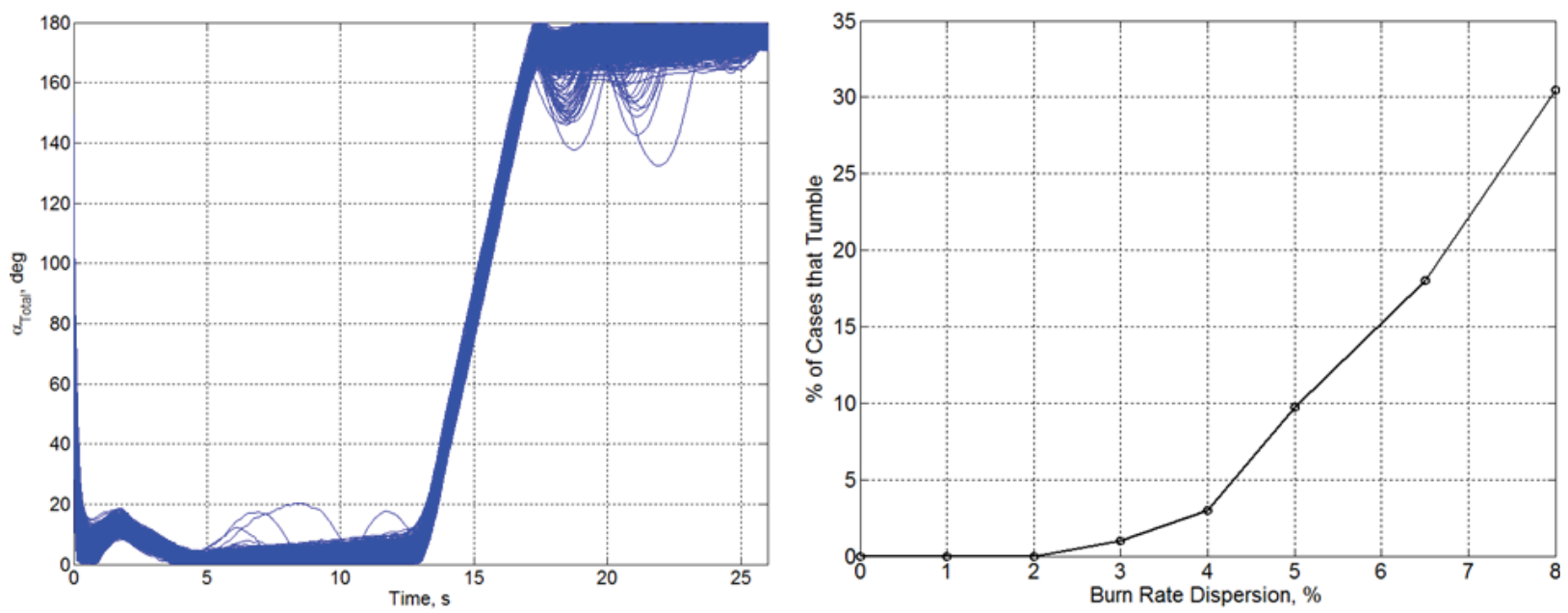

Figure 23. Monte Carlo results evaluating off-nominal thrust dispersions for OS-1. 
during the pre-reorientation coast. The second plot shows the results as the burn rate dispersion was increased. Even with a $5 \%$ burn rate dispersion, only $10 \%$ of the cases tumbled out of control. It is anticipated that these results would improve even further with a more sophisticated control algorithm (the controller used in this feasibility analysis was very basic).

\section{Conclusion}

This paper investigates the performance and flight dynamic feasibility of two towerless crew escape system concepts. Both designs offer an alternative to the tower-configuration crew escape systems used in the Mercury and Apollo Programs and now baselined for the Orion Multi-purpose Crew Vehicle. Elimination of the launch escape tower has the potential to improve integration of the escape system with the launch vehicle providing numerous benefits such as lower induced aero acoustic loads and a decrease in bending moments during ascent.

Both escape system concepts that were considered feature a Sears-Haack shaped forward fairing that fully encapsulates the CM capsule and solid rocket escape motors equipped with TVC that propel the CM away from the launch vehicle in the event of an abort and maintain stability during the escape maneuver. The concepts differ in their approach to maintaining stability during coasting flight as well as the manner in which they reorient the CM to a heat shield forward orientation prior to escape system jettison and deployment of the CM parachutes. The allpropulsive concept (OS-1) makes use of liquid attitude control thrusters for active control during coast and reorientation. The aero stable concept (OS-2) deploys aft-swept grid fins to provide static stability after escape motor burnout and utilizes mortar fired drogue parachutes to effect reorientation.

Through 6DOF simulation analysis, each concept was shown to be controllable and capable of meeting representative escape requirements at four critical points along an Ares I launch vehicle ascent trajectory. Off nominal performance was also shown to be adequate for a range of system dispersions and uncertainties that were modeled. Both concepts were most sensitive to thrust dispersions which are an inherent risk in a design using six separate solid rocket escape motors that are fired simultaneously. The unexpected thrust moments caused by the thrust dispersions could be made more manageable if the escape motor thrust profile included a smooth, gradual thrust tail off.

The results of these studies demonstrate an initial level of feasibility for both escape system concepts. Future analysis will incorporate a more sophisticated, flight-like control system, evaluate the effect of additional system uncertainties and examine escape system performance at more points along the ascent trajectory.

\section{Acknowledgments}

The authors wish to gratefully acknowledge Dave Shemwell for conceptual design consultation, Craig Newland for vehicle design and layout, Robert Garcia and George Story for development of propulsion models, and Mike Mendenhall for aerodynamic database development. In addition, Jennifer Madsen and Eugene Heim provided significant technical consultation on simulation modeling as well as extensive verification of simulation results. Finally, the authors would also like to thank Brett Starr for reviewing the paper, Michael Sean Walsh for creating the graphic art, and Kay Forrest and Anne Rhodes for preparing the final manuscript.

\section{References}

\footnotetext{
${ }^{1}$ Townsend, N. A., “Apollo Experience Report—Launch Escape Propulsion Subsystem,” NASA Technical Note D-7083," Washington D.C., March 1973.

2 McCarthy, J. F., Dodds, J. I., and Crowder, R. S., "Development of the Apollo Launch Escape System," Journal of Spacecraft, Vol. 5, No. 8, pp. 927-932.

${ }^{3}$ Davidson, J., Madsen, J., Proud, R., Merritt, D., Raney, D., Sparks, D., et al., "Crew Exploration Vehicle Ascent Abort Overview," AIAA 2007-6590.

${ }^{4}$ Dennehy, C. J., Lanzi, R. J., and Ward, P. R., “GN\&C Design Overview and Flight Test Results from NASA's Max Launch Abort System (MLAS)," AIAA 2010-9432.

${ }^{5}$ Washington, W. D., and Miller, M. S., “Grid Fins - A New Concept for Missile Stability and Control,” AIAA $1993-0035$.

${ }^{6}$ Pruzan, D. A., Mendenhall, M. R., Rose, W. C., and Schuster, D. M., "Grid Fin Stabilization of the Orion Launch Abort Vehicle," AIAA 2011-3018

${ }^{7}$ Brauer, G. L., Cornick, D. E., and Stevenson, R., "Capabilities and Applications of the Program to Optimize Simulated Trajectories (POST)," NASA CR-2770, Feb. 1977.

${ }^{8}$ Capone, F. J., "Post-Test Results from the Force/Moment Test of the 8\%-Scale MLAS Configuration in the Calspan Transonic Wind Tunnel," ViGYAN Inc., Hampton, VA, Report No. R08-020, 2008.

${ }^{9}$ Aerodynamic Analysis Group, North American Aviation, I., “Aerodynamic Data Manual for Project Apollo," SID 64-174C, January 1965, revised February, 1966.

10 Justus, C. G., and Leslie, F. W., "The MSFC Earth Global Reference Atmospheric Model - 2007 Version," NASA TM2008-215581, Nov. 2008.
} 